\title{
The elusive nature of the blocking effect: 15 failures to replicate
}

\author{
Elisa Maes ${ }^{1}$, Yannick Boddez ${ }^{1}$, Joaquín Matías Alfei ${ }^{1}$, Angelos-Miltiadis Krypotos ${ }^{2}$, Rudi \\ $D^{\prime}$ Hooge $^{1}$, Jan De Houwer ${ }^{3}$, Tom Beckers ${ }^{1,4}$ \\ ${ }^{1} \mathrm{KU}$ Leuven, Belgium \\ ${ }^{2}$ Utrecht University, The Netherlands \\ ${ }^{3}$ Ghent University, Belgium \\ ${ }^{4}$ University of Amsterdam, The Netherlands
}

IN PRESS. JOURNAL OF EXPERIMENTAL PSYCHOLOGY: GENERAL

Elisa Maes: Tiensestraat 102 box 3712, 3000 Leuven, Belgium

Yannick Boddez: Tiensestraat 102 box 3712, 3000 Leuven, Belgium

Joaquín Matías Alfei: Tiensestraat 102 box 3712, 3000 Leuven, Belgium

Angelos-Miltiadis Krypotos: Heidelberglaan 1, 3584 CS Utrecht, The Netherlands

Jan De Houwer: Henri Dunantlaan 2, 9000 Ghent, Belgium

Rudi D'Hooge: Tiensestraat 102 box 3714, 3000 Leuven, Belgium

Tom Beckers: Tiensestraat 102 box 3712, 3000 Leuven, Belgium

Corresponding author:

Tom Beckers

TEL: +32 16326134

FAX: +32 16326099

E-mail: tom.beckers@kuleuven.be 


\begin{abstract}
With the discovery of the blocking effect, learning theory took a huge leap forward, because blocking provided a crucial clue that surprise is what drives learning. This in turn stimulated the development of novel association-formation theories of learning. Eventually, the ability to explain blocking became nothing short of a touchstone for the validity of any theory of learning, including propositional and other non-associative theories. The abundance of publications reporting a blocking effect and the importance attributed to it suggest that it is a robust phenomenon. Yet, in the current paper we report fifteen failures to observe a blocking effect despite the use of procedures that are highly similar or identical to those used in published studies. Those failures raise doubts regarding the canonical nature of the blocking effect and call for a reevaluation of the central status of blocking in theories of learning. They may also illustrate how publication bias influences our perspective towards the robustness and reliablilty of seemingly established effects in the psychological literature.
\end{abstract}

Keywords: blocking, replicability, associative learning theory, prediction error, surprise 


\section{INTRODUCTION}

Ivan Pavlov's (1927) experiments on classical conditioning in dogs were a milestone in the study of elementary learning processes. The paradigm he introduced allowed researchers to investigate the psychological principles underlying associative learning in a relatively simple and highly controlled and systematic manner (Delamater \& Lattal, 2014). In a classical conditioning experiment, presentations of a conditioned stimulus (CS) are repeatedly followed by presentations of an unconditioned stimulus (US). As a result, the CS comes to elicit a conditioned response (CR) that it did not elicit before. Early psychological theories of learning (e.g. Bush \& Mosteller, 1951) assumed that the mere co-occurrence of the CS and the US in space and time (i.e., spatiotemporal contiguity) was sufficient for this type of learning to occur. This idea was challenged by the observation of stimulus competition. It was Kamin who, with the discovery of the blocking effect (Kamin, 1969), suggested an alternative driving force for learning: surprise. The design and results of his blocking experiment are shown in Figure 1. The experiment consisted of three phases. In the first phase, the experimental group received several presentations of a noise followed by a foot shock US ( $\mathrm{N}+$ training). In the second phase, both the experimental and control group received presentations of the noise compounded with a light followed by foot shock (NL+ training). Thus, the difference between both groups was that the experimental group was conditioned to the noise before receiving compounded presentations of noise and light followed by shock, while the control group was not previously conditioned to the noise. In the third phase, Kamin tested conditioned responding to the light when it was presented alone. If contiguity is the sole determinant of learning, then no between-group difference should have been observed, because both groups received an equal number of light-shock pairings. As can be seen in Figure 1, Kamin found something else. Whereas the control group showed a strong CR to the light, the experimental group, which received conditioning to the noise before receiving pairings of the noise and light compound with shock, only showed a weak CR to the light. Prior conditioning with the noise appeared to have "blocked" conditioning to the light. 
A

\begin{tabular}{llll} 
Group & Phase 1 & Phase 2 & Test \\
\hline Experimental & $16 \mathrm{~N}+$ & $8 \mathrm{LN}+$ & L? \\
Control & & $8 \mathrm{LN}+$ & L? \\
\hline
\end{tabular}

B

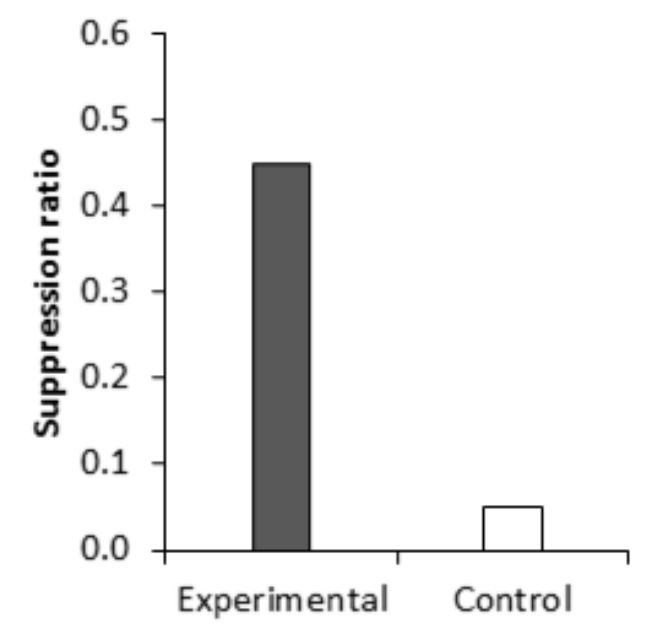

Figure 1. A. Design of Kamin's blocking experiment. The + represent the presentation of a foot shock, $\mathrm{N}$ the presentation of a noise and $\mathrm{L}$ the presentation of a light. B. Conditioned responding for the test trials for experimental and control group expressed as a suppression ratio. A suppression ratio of 0 corresponds to a strong conditioned response and a ratio of 0.5 corresponds to a complete lack of conditioned responding (After Kamin, 1969).

On the basis of this observation, Kamin suggested that surprise is critical for learning. In the experimental group, as a result of the first phase of training, the noise came to reliably predict the shock. Therefore the shock was not surprising in the second phase, and learning about the light was said to be blocked. The role of surprise in learning has since been conceptualized in various ways (Holland, 1988). Perhaps most explicit was the formalization of surprise in the Rescorla-Wagner model of associative learning as prediction error (i.e. the discrepancy between expected and actual US occurrence) (Kamin, 1969; Rescorla \& Wagner, 1972). Since Rescorla and Wagner (1972) introduced the notion of prediction error, it has become a highly influential concept for the understanding of learning on behavioral, brain and even neuronal levels (e.g. Colombo, 2014; Corlett et al., 2004; den Ouden et al., 2009; Schultz \& Dickinson, 2000; Steinberg et al., 2013; Tobler et al., 2006). Other theories have followed in its footsteps to suggest that surprise is necessary to engage association formation processes (e.g. Mackintosh, 1975; Pearce \& Hall, 1980). Although most often explained in term of surprise, the blocking effect has also been explained by alternative theories of 
learning that do not ascribe a central role to prediction error in association formation, such as the comparator hypothesis (e.g. Miller \& Matzel, 1988).

The capacity to explain blocking became nothing short of a touchstone for the validity of a theory of associative learning and until today, conditioning researchers use (variations of) the blocking effect to pit weaknesses and strengths of different theories of associative learning against each other (e.g. Blaisdell, Gunther, \& Miller, 1999; Boddez, Baeyens, Hermans, \& Beckers, 2011; P. M. Jones \& Haselgrove, 2013; Mackintosh, 1971; Williams, 1996). Furthermore, blocking procedures have been used to distinguish between association-formation theories and rule-based or statistical theories of learning. For example, observations of the blocking effect in human causal learning tasks (Dickinson, Shanks, \& Evenden, 1984) and social attribution tasks (van Overwalle \& van Rooy, 2001) have been taken as support for the idea that associative processes play a crucial role in those phenomena (for a critical discussion of this argument see Boddez, De Houwer, \& Beckers, in press). The impact and importance of the blocking effect is further demonstrated by its omnipresence in the literature. Today, blocking has been reported using a wide variety of experimental procedures - for example appetitive and aversive learning protocols (e.g., Jennings \& Kirkpatrick, 2006; Kamin 1969), taste-aversion protocols (e.g., Willner, 1978), spatial learning (e.g., Rodrigo, Chamizo, McLaren, \& Mackintosh, 1997) and human causal learning tasks (e.g., Dickinson et al., 1984) - and in a variety of species - including humans (e.g., Dickinson et al., 1984), rodents (e.g., Kamin, 1969), rabbits (e.g., Merchant \& Moore, 1973), honey bees (e.g., Smith \& Cobey, 1994), as well as mollusks (e.g., Sahley, Rudy, \& Gelperin, 1981) and snails (e.g., Prados et al., 2013).

Some 10 years ago, we set out to establish a blocking procedure that would yield a robust blocking effect and could thus serve as a starting point to investigate the cognitive and neurobiological processes involved in blocking in rodents. Given our own previous successes in obtaining blocking effects (Beckers, Miller, De Houwer, \& Urushihara, 2006; Wheeler, Beckers, \& Miller, 2008), the abundance of publications reporting a blocking effect, and the importance attributed to it, we did not anticipate substantial problems in establishing such a procedure. Here, 
however, we report a series of fifteen rodent experiments in which we tried but failed to obtain a robust blocking effect. Collectively, those 15 experiments represent the full record of all blocking studies in non-human animals executed or supervised by the last author since $2004^{1}$. In the first 14 of those experiments, various species, strains, experimental procedures, parameters and set-ups were used. The procedures employed here were always based on published studies and while not identical to those previous reports in every detail, some came rather close to being exact replications (see Appendix A for a comparison between our protocols and the protocols used in published studies). Nonetheless, we either failed to obtain a blocking effect or when we found indications for a blocking effect were then unable to replicate that effect in follow-up experiments. Power analyses suggested that the absence of a blocking effect was not likely to be due to a lack of power (see Appendix E for details). Despite being relatively close replications, it cannot be excluded that we somehow deviated from previous studies that successfully demonstrated blocking in important ways. Therefore, we additionally performed a highly powered exact replication that adhered strictly to the protocol of a published study that did demonstrate a blocking effect; it did not yield a blocking effect either.

In all experiments described below, the experiments consisted of three phases (see Table 1). In the first phase (Elemental Training), animals in the blocking group received pairings of a stimulus A with the US, while animals in the control group received an equal number of pairings of a different stimulus B with the US. In the second phase (Compound Training), animals in both groups received presentations of stimulus compound AX followed by the US. In the third phase (Test), X was presented alone, without the US. Importantly, while Kamin completely omitted Phase 1 training in the control group, we used a B control condition, which is regarded as the most appropriate of the control groups commonly used in blocking experiments (Arcediano, Escobar, \& Matute, 2001;

\footnotetext{
${ }^{1}$ Apart from two early studies for which crucial details could not be recovered (both of which were
} unsuccessful in producing blocking). 
Taylor, Joseph, Balsam, \& Bitterman, 2008, see the General Discussion for an elaborate discussion of the different control procedures used in blocking designs).

Table 1

General design of the experiments

\begin{tabular}{lccc}
\hline Group & Elemental & Compound & Test \\
\hline Experimental & $\mathrm{A}+$ & $\mathrm{AX}+$ & $\mathrm{X}$ \\
Control & $\mathrm{B}+$ & $\mathrm{AX}+$ & $\mathrm{X}$ \\
\hline
\end{tabular}

Note. The + represents the delivery of a US; A, B and X represent different auditory and/or visual stimuli.

In what follows, the procedures and results of fifteen experiments are described, subdivided

in five series according to the species and strain of animals used and the general procedure applied.

For each series, a general description of subjects, materials and methods is provided first, followed

by the specifics for each experiment and then the results. An overview of the stimuli used in all experiments can be found in Appendix B and an overview of the procedures in Appendix C. For comparability, we first present the results of classic frequentist analyses as typically reported in previous blocking studies. After the presentation of the five series of experiments and their results, we present the results of a Bayesian meta-analysis across all 15 studies. Then we turn to a discussion of what our consistent failure to obtain a solid blocking effect implies for theories of associative learning (be it association-formation theories, propositional theories or others) and for the reliability and replicability of psychological phenomena in general.

\section{SERIES 1 (EXPERIMENTS 1-4): FAILURE TO OBTAIN BLOCKING IN AVERSIVE}

\section{CONDITIONING IN C57BL/6J MICE}

Method

\section{General overview}

In four experiments, female and male mice were trained in a conditioned suppression procedure, in which interference with nose-poking for food pellets was measured to assess 
conditioned fear in food-deprived subjects. To our knowledge, no previous articles on blocking in mice had been published at the time those experiments took place (2004-2007). However, various studies (e.g. D. Jones \& Gonzalez-Lima, 2001; Mackintosh, Dickinson, \& Cotton, 1980) had reported successful blocking in rats with similar stimuli and a similar procedure as were employed in the present studies (see Table A1 in Appendix A for a comparison with those previous studies and Table B1 and C1 in Appendix B and C, respectively, for an overview of the stimuli and procedure used in this series).

\section{Subjects}

Subjects were experimentally naïve C57BL/6J mice obtained from our own breeding colony. The animals were housed in cages in a vivarium maintained on a 12-h day/night cycle. The animals were allowed free access to water, whereas food availability was limited to 30 min per day following a progressive deprivation schedule initiated one week prior to the start of the study.

Experiment 1. Subjects were 24 male mice with body weights ranging from 19.1 to $29.7 \mathrm{~g}$ before deprivation. During the experiment, three animals died of unknown cause. As a result, 11 mice remained in the experimental group and 10 mice in the control group.

Experiment 2. Subjects were 24 male mice with body weights ranging from 24.7 to $30.0 \mathrm{~g}$ before deprivation. Both groups consisted of 12 mice.

Experiment 3. Subjects were 24 male mice with body weights ranging from 17.7 to $21.7 \mathrm{~g}$ before deprivation. During the experiment, two animals died of unknown cause, leaving 11 mice in each groups.

Experiment 4. Subjects were 20 mice (15 females) with body weights ranging between $19.2 \mathrm{~g}$ and $24.7 \mathrm{~g}$ for females and between $26.7 \mathrm{~g}$ and $31.5 \mathrm{~g}$ for males at the beginning of the experiment. The experimental group consisted of 10 mice, all female. The subjects in this experiment were part of a larger cohort that also included mGLUR7 knock-out mice; the knock-out animal data are not reported here. 


\section{Apparatus}

Four operant chambers $(18 \mathrm{~cm}$ length $\times 18 \mathrm{~cm}$ width $\times 30 \mathrm{~cm}$ height; Coulbourn Instruments, Allentown, PA, USA) were used in Experiments 1 and 2, while eight chambers were used in Experiments 3 and 4. In Experiment 4, those operant chambers were contained in isolation cubicles (Coulbourn Instruments, Allentown, PA, USA); this was not the case in the other three experiments. All chambers had metal ceilings and side walls, and clear Plexiglas front and back walls. The floor was constructed of stainless steel grids ( $0.5 \mathrm{~cm}$ in diameter), through which a foot shock could be delivered. In each chamber, there was a nose poke hole equipped with an infra-red beam, which could be illuminated by means of a tri-light, and opposite to the nose poke hole was a recess. A food dispenser that could deliver 20-mg food pellets (Noyes precision pellets; Research Diets, New Brunswich, NJ) into the recess, which could be illuminated by a white light, was positioned on the opposite wall. Pellet delivery was indicated by the offset of the tri-light in the nose poke operandum and illumination of the food recess for $5 \mathrm{~s}$. The enclosure could be illuminated by a house light. A speaker mounted on the wall was used to deliver tones with frequencies from $1000 \mathrm{~Hz}$ to $3500 \mathrm{~Hz}$. All CSs were $30 \mathrm{~s}$ in duration. See Appendix B, Table B1 for an overview of the stimuli used in each experiment.

Experiment 1. The experiment was run in the dark. The flashing ( $0.5 \mathrm{~s}$ on/ $0.5 \mathrm{~s}$ off) and steady illumination of the house light served as stimulus A and B, counterbalanced. A pulsing $3500-\mathrm{Hz}$ tone (200 ms on/200 ms off) served as stimulus X. The US was a 0.5-s, 0.1-mA foot shock.

Experiments 2. The house light remained on, unless it was flashing ( $0.2 \mathrm{~s}$ off/ $1.3 \mathrm{~s}$ on) to serve as stimulus X. A steady $1000-\mathrm{Hz}$ tone and a complex, pulsing tone $[1500 \mathrm{~Hz}(0.1 \mathrm{~s}$ on/ $0.5 \mathrm{~s}$ off) and $2500 \mathrm{~Hz}$ ( $0.5 \mathrm{~s}$ on/ $0.1 \mathrm{~s}$ off)] served as stimulus $A$ and B, counterbalanced. The US was the same as for Experiment 1.

Experiment 3. The stimulus parameters employed in this experiment were identical to Experiment 2, except for the US which was a 0.5-s, 0.2-mA foot shock. 
Experiment 4. The experiment was run in the dark. The flashing and steady illumination of the house light served as stimulus A and B, as in Experiment 1. A tone served as stimulus X. The US was a $0.5-\mathrm{s}, 0.2-\mathrm{mA}$ foot shock.

\section{Procedure}

The experiments in this series were run in a mice lab at KU Leuven. The actual blocking training was preceded by a shaping phase to train the animals to nose pose for food. Each shaping session was 30 min long, while each training session was 25 min long. Appendix C, Table C1 provides an overview of the number of training days in each training phase for each experiment.

Shaping. Standard procedures were used to train the mice to nose poke for food pellets. A fixed time 120-s (FT 120-s) schedule of non-contingent pellet delivery operated concurrently with a continuous reinforcement (CRF) schedule at the start of shaping; shaping ended on a variable interval (VI) 20-s (Experiment 1) or a VI 30-s (Experiments 2 to 4) schedule. After shaping, the nose poke operandum was covered, except for Experiment 4, where pellets were delivered during all phases on a VI 30-s schedule.

Habituation. Animals in Experiment 3 were given one day of habituation training to $\mathrm{X}$ and animals in Experiment 4 were given one day of habituation training to $A, B$ and $X$ prior to the start of the experiment. No habituation to the CSs was provided in Experiments 1 and 2, but animals could habituate to the context during the shaping phase.

Phase 1: Elemental training. Experimental animals were exposed daily to three pairings of $A$ with the US, with A and the US coterminating. The control animals received similar pairings of B with the US. The number of elemental training days differed for each experiment (see Table C1).

Phase 2: Compound training. All animals received daily three pairings of the AX compound with the US, with the compound and the US coterminating. Animals in Experiments 1 to 3 received only one day of compound training. Animals in Experiment 4 received four days of compound training (see Table C1). 
Reshaping. The nose poke holes were made accessible again (Experiments 1 to 3 ), and all animals were retrained to nose poke for pellets.

Test. All animals were tested on X, which was presented four times during a 30-min session. Pellets were delivered on a VI 30-s schedule. No pellets were delivered during a 1-min period immediately preceding the CS (this preCS period was only $30 \mathrm{~s}$ in Experiment 4) and during the CS period.

\section{Results}

Data and analysis scripts for these and all following experiments are available at Open Science Framework (https://osf.io/fcwnr/?view only=754693fa2907497a9ad8013a63813781). All statistical analyses were conducted with JASP version 0.7.1 (Love et al., 2015), which has a number of advantages over other statistical packages. First, JASP allows one to select a direction when conducting a one-tailed $t$-test, making the resulting $p$-values easier to interpret. Second, JASP allows one to calculate a Bayesian $t$-test (see below, Bayesian Analysis).

Mean suppression ratios were calculated as the mean number of nose pokes during presentations of $X$ divided by the sum of this number and the mean number of responses per $30 \mathrm{~s}$ during the preCS period. Figure 2 depicts the mean suppression ratio across all presentations of $X$ for experimental and control groups, for Experiments 1 to 4. The difference between the suppression ratio for the experimental group and the control group in Experiments 2 and 4 was numerically in line with a blocking effect; however, it failed to reach significance [smallest $p=.15$ (one-tailed)]. No indications for a blocking effect were obtained in any of the other experiments in this series (see Appendix D, Table D1 for detailed statistics). To ascertain that the results were not due to differences in preCS responding between groups, we compared preCS responding before the first presentation of $X$ between groups for all experiments. No baseline differences were observed in any of the four experiments (see Appendix D, Table D2 for detailed statistics). Power analyses on the basis of the effect sizes reported in the most similar published blocking studies (see Appendix E for details) 
suggested that the absence of a blocking effect was not due to a lack of power (estimated power > 0.90 for all experiments).

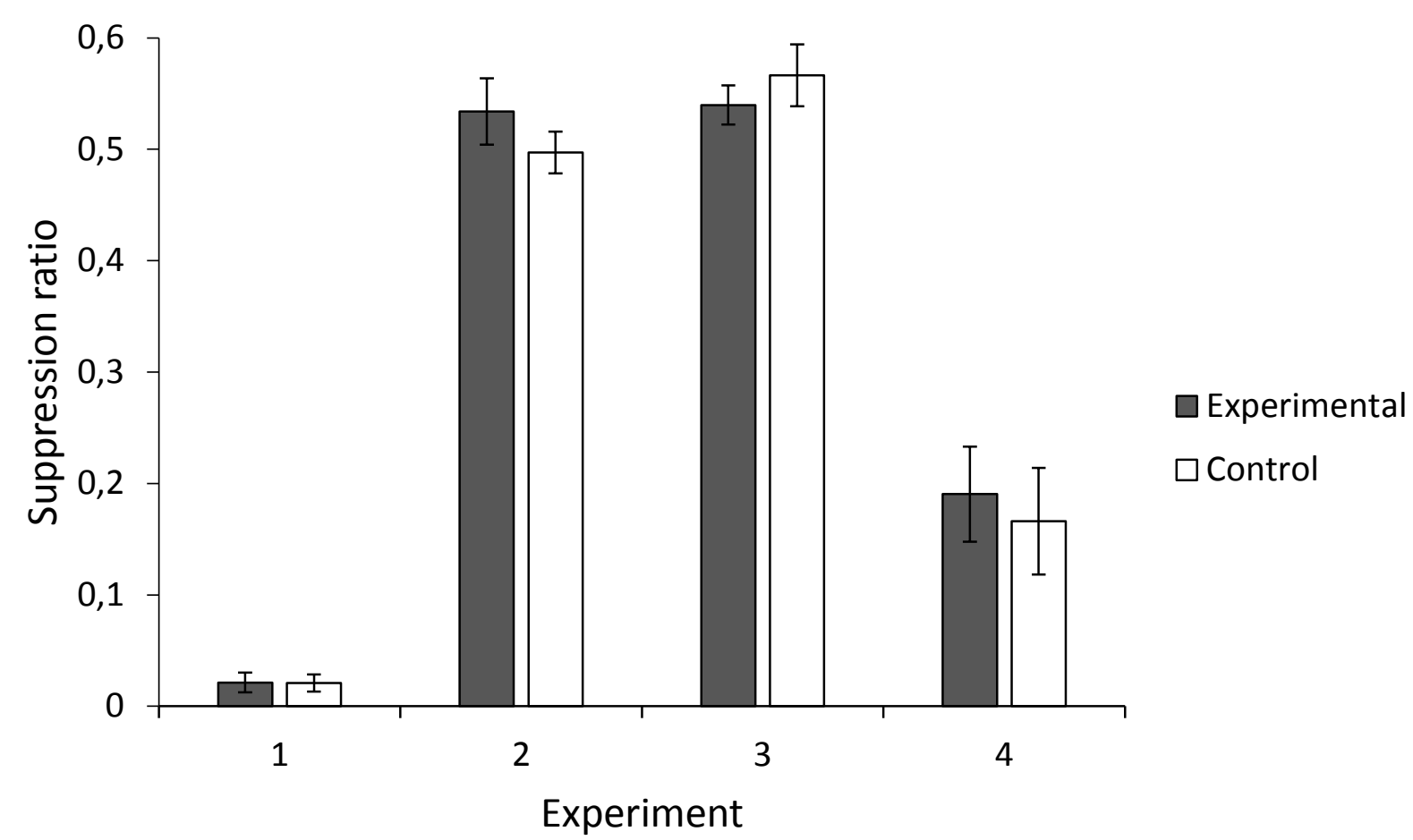

Figure 2: Mean suppression ratio at test across all presentations of $\mathrm{X}$ for experimental and control groups, for Experiments 1 to 4. Error bars represent standard errors of the means.

SERIES 2 (EXPERIMENTS 5-6): FAILURE TO OBTAIN BLOCKING IN AVERSIVE CONDITIONING IN LONG-EVANS AND SPRAGUE-DAWLEY RATS

Method

General overview

In two experiments, female rats were trained in a conditioned suppression procedure, in which interference with lever-pressing for a sucrose solution was measured to assess conditioned fear in food-deprived subjects. The procedure of these experiments was highly similar to previously conducted studies that had demonstrated a blocking effect in which we were involved (Beckers et al., 2006; Wheeler et al., 2008) (see Table A2 in Appendix A for a comparison with those previous studies 
and Table B1 and C1 in Appendix B and C, respectively, for an overview of the stimuli and procedure used in this series).

\section{Subjects}

Subjects were experimentally naïve, female rats obtained from Harlan (Indianapolis, IN). The animals were pair-housed in a vivarium maintained on a 14/10 hr dark/light cycle. The animals were allowed free access to water, whereas food availability was limited to $15 \mathrm{~g}$ per day per rat following a progressive deprivation schedule initiated one week prior to the start of the study. Experiments were conducted during the dark portion of the cycle. The subjects in these experiments were part of a larger experiment involving four groups. Animals in the other two groups were given subadditive pretraining before the start of blocking training, which has been reported to diminish blocking (Beckers et al., 2006), and were therefore not included in the analyses.

Experiment 5: Subjects were 24 ( $n s=12$ ) Long-Evans rats with body weights ranging from 225 to $249 \mathrm{~g}$ before the start of the experiment.

Experiment 6: Subjects were 24 ( $n s=12$ ) Sprague-Dawley rats with body weights ranging from 225 to $249 \mathrm{~g}$ before the start of the experiment.

\section{Apparatus}

Eight standard operant chambers $(30 \mathrm{~cm}$ length $\times 25 \mathrm{~cm}$ width $\times 20 \mathrm{~cm}$ height; Med Associates, Georgia, VT) placed in sound- and light-resistant isolation cubicles were used (Med Associates, Georgia, VT). All chambers had Plexiglas front and back walls and ceilings, and aluminum side walls. The floors were constructed of stainless steel grids $(0.5 \mathrm{~cm}$ in diameter), through which a 0.5-s, 0.5-mA foot shock could be delivered. In each chamber, there was an operant lever, and adjacent to the lever was a recess. A water dipper could deliver $0.05 \mathrm{cc}$ of a sucrose solution (20\%) into a cup on the bottom of a recess. The enclosure was dimly illuminated by a house light. A diffuse light, placed on the opposite wall of the house light, was used to deliver a flashing light $(0.25 \mathrm{~s} \mathrm{on/}$ $0.25 \mathrm{~s}$ off). The house light was turned off when the diffuse light was flashing. Two speakers, 
mounted on the outside walls of the chamber, were used to deliver a $3000-\mathrm{Hz}$ tone ( $70 \mathrm{dBA})$ and a white noise (70 $\mathrm{dBA})$ respectively. A third speaker was used to deliver a $300-\mathrm{Hz}$ tone (70 $\mathrm{dBA})$ or a click train stimulus (4 clicks/s, $70 \mathrm{dBA}$ ), which served as stimuli A and B, counterbalanced. The 3000 $\mathrm{Hz}$ tone and the flashing light served as stimulus $\mathrm{C}$ and $\mathrm{D}$, counterbalanced. The white noise served as stimulus X. All CSs were $30 \mathrm{~s}$ in duration. For an overview of the stimuli used in each experiment, see Appendix B, Table B1.

\section{Procedure}

The experiments in this series were run in a rat lab at the University of California, Los Angeles. The actual blocking training was preceded by a shaping phase to train the animals to lever press for the sucrose solution. Each session was 60 min long. Appendix C, Table C1 provides an overview of the number of training days in each training phase for each experiment.

Shaping. Standard procedures were used to train the rats to press the lever for the sucrose solution. A FT 120-s schedule operated concurrently with a CRF schedule at the start of shaping; shaping ended on a VI 30-s schedule.

Phase 1: Pretraining. During the four days of pretraining, all animals were exposed daily to two pairings of $C$ with the US and one pairing of $D$ with the US, with the stimulus and the US coterminating. The levers were retracted after shaping.

Phase 2: Elemental training. During the three days of elemental training, experimental animals were exposed daily to four pairings of A with the US, with A and the US coterminating. The control animals received similar pairings of $B$ with the US.

Phase 3: Compound training. During a single compound training session, all animals were exposed to four pairings of the AX compound with the US, with the compound and the US coterminating.

Reshaping. The levers were inserted again and all animals were retrained to lever press for the sucrose solution. 
Test. All animals were tested on X, which was presented four times, during a 30-min session. Sucrose solution was delivered on a VI 20-s schedule.

\section{Results}

Mean suppression ratios were calculated as above. Figure 3 presents the mean suppression ratio across all presentations of $X$ for experimental and control groups, for Experiments 5 and 6 . The difference between the suppression ratio for the experimental group and the control group in Experiment 5 was numerically in line with a blocking effect; however, it failed to reach significance $[t(22)=1.45 p=0.08$ (one-tailed)]. There was no indication whatsoever for a blocking effect in Experiment 6 (see Appendix D, Table D1 for detailed statistics). To ascertain that the results were not due to differences in preCS responding between groups, we compared preCS responding before the first presentation of $X$ between groups for both experiments. No baseline differences were observed in any of the two experiments (see Appendix D, Table D2 for detailed statistics). Power analyses on the basis of the effect sizes reported in the most similar published blocking studies (see Appendix E for details) suggested that the absence of a blocking effect was not due to a lack of power (estimated power $>.90$ for both experiments).

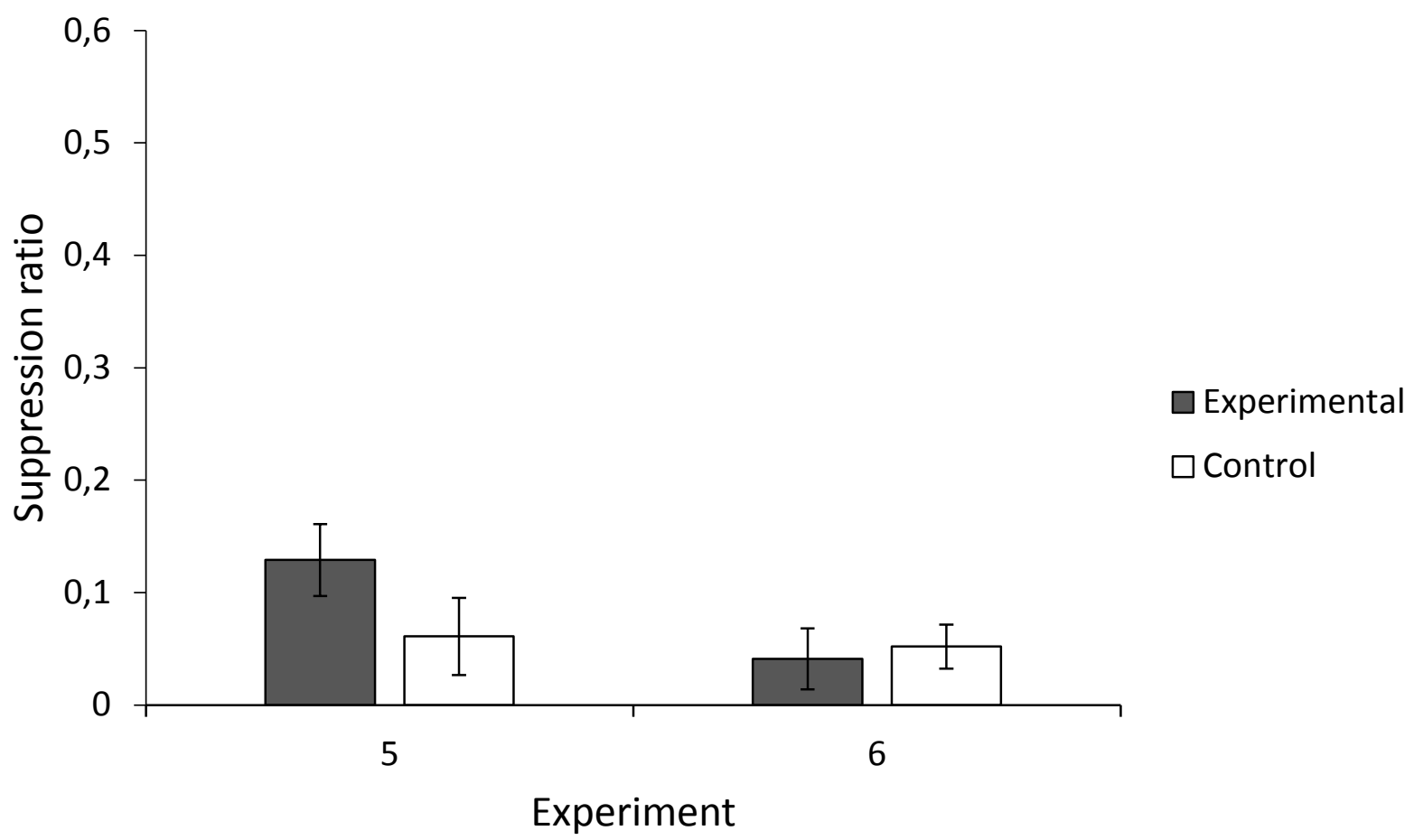


Figure 3: Mean suppression ratio at test across all presentations of $\mathrm{X}$ for experimental and control groups, for Experiments 5 and 6. Error bars represent standard errors of the means.

\section{SERIES 3 (EXPERIMENTS 7-10): FAILURE TO OBTAIN BLOCKING IN AVERSIVE CONDITIONING IN SPRAGUE-DAWLEY RATS}

Method

General overview

In four experiments, female and male rats were trained in a conditioned suppression procedure, in which interference with lever-pressing for water was measured to assess conditioned fear in waterdeprived subjects. The procedure of those experiments was again similar to previous reported studies that have demonstrated a blocking effect (Beckers et al., 2006; Blaisdell et al., 1999; Wheeler et al., 2008) (see Table A3 in Appendix A for a comparison with those previous studies and Table B1 and C1 in Appendix B and C, respectively, for an overview of the stimuli and procedure used in this series).

\section{Subjects}

Subjects were experimentally naïve, Sprague-Dawley rats obtained from Janvier (Le GenestSaint-Isle, France). The animals were pair-housed in standard cages in a room with a 12-h day-night cycle. The animals were allowed free access to food, whereas water availability was limited to 20 min per day following a progressive deprivation schedule initiated one week prior to the start of the study.

Experiment 7. Subjects were $8(n s=4)$ male rats with body weights ranging from 285 to 310 g before deprivation.

Experiment 8 . Subjects were $8(\mathrm{~ns}=4)$ male rats with body weights ranging from 295 to 330 g before deprivation. 
Experiment 9. Subjects were $8(\mathrm{~ns}=4$ ) female rats with body weights ranging from 210 to $225 \mathrm{~g}$ before deprivation.

Experiment 10 . Subjects were 8 (ns $=4$ ) female rats with body weights ranging from 258 to $270 \mathrm{~g}$ before deprivation.

\section{Apparatus}

Eight standard operant chambers ( $34 \mathrm{~cm}$ length $\times 33 \mathrm{~cm}$ width $\times 33 \mathrm{~cm}$ height; Coulbourn Instruments, Allentown, PA, USA) housed in isolation cubicles (Med Associates Inc.) were used. All chambers had metal ceilings and side walls and clear Plexiglas front and back walls. The floors were constructed of stainless steel grids $(0.5 \mathrm{~cm}$ in diameter), through which a 0.5 -s foot shock could be delivered. In each chamber, there was an operant lever, and adjacent to the lever was a recess. A water dipper could deliver $0.04 \mathrm{cc}$ of water into a cup on the bottom of the recess. Water delivery was indicated by the onset of a white noise for $0.5 \mathrm{~s}$ and the illumination of the recess for $1 \mathrm{~s}$. The enclosure was dimly illuminated by a house light. Two speakers were mounted on two different interior walls. One speaker was used to deliver a white noise ( $83 \mathrm{dBC}$ in Experiments 7 and 8; $79 \mathrm{dBC}$ in Experiments 9 and 10). The other speaker was used to deliver a $1000-\mathrm{Hz}(79 \mathrm{dBC})$ or $3000-\mathrm{Hz}$ tone (87 dBC), which served as stimulus A and B, counterbalanced. A clicker mounted on each environmental chest was able to deliver a clicking sound and served as stimulus $X$ ( $85 \mathrm{dBC}$ in Experiment 7 and $80 \mathrm{dBC}$ in Experiments 8 to 10). All CSs were $30 \mathrm{~s}$ in duration. For an overview of the stimuli used in each experiment, see Appendix C, Table C1.

\section{Procedure}

The experiments in this series were run in a rat lab at KU Leuven. The actual blocking training was preceded by a shaping phase to train the animals to lever press for water. Each session was 60 min long. Appendix C, Table C1 provides an overview of the number of training days in each training phase for each experiment.

Shaping. Standard procedures were used to train the rats to press the lever for water. A FT 120-s schedule operated concurrently with a CRF schedule at the start of shaping in Experiments 7, 8 
and 9, while the FT 120-s schedule operated alone on the first day of shaping in Experiment 10; shaping ended on a VI 20-s schedule. For Experiments 7 to 9, the levers were retracted after shaping.

Phase 1: Elemental training. During the three elemental training days, experimental animals were exposed daily to four pairings of A with the US, with A and the US coterminating. The control animals received similar pairings of $B$ with the US.

Phase 2: Compound training. During a single compound training session, all animals received four pairings of the AX compound with the US, with the compound and the US coterminating. Reshaping. The levers were inserted again (Experiment 7 to 9) and the animals were retrained to lever press for water.

Test. All animals were tested on $\mathrm{X}$, which was presented three times (Experiments 7 and 8) or four times (Experiments 9 and 10), during a 30-min session. Pellets were delivered on a VI 20-s schedule.

\section{Results}

Mean suppression ratios were calculated as above. Figure 4 depicts the mean suppression ratio across the first three presentations of $\mathrm{X}$ for experimental and control groups, for Experiment 7 to 10 . The difference between the suppression ratio for the experimental group and the control group in Experiments 7 and 8 was numerically in line with a blocking effect; however, it failed to reach significance [smallest $p=0.10$ (one-tailed)]. However, it is clear from Figure 4 that not a hint of a blocking effect was observed in Experiments 9 and 10 (see Appendix D, Table D1 for detailed statistics). So, a trend for a blocking effect was observed in two experiments, but we were not able to replicate the effect in two further experiments using similar procedures. To ascertain that the results were not due to differences in preCS responding between groups, we compared preCS responding before the first presentation of $\mathrm{X}$ between groups for all experiments. No baseline differences were observed in any of the four experiments (see Appendix D, Table D2 for detailed statistics). Despite the rather small sample sizes, power analyses on the basis of the effect sizes reported in the most 
similar published blocking studies (see Appendix E for details) suggested that the absence of a blocking effect was not likely to be due to a lack of power (estimated power $>.70$ for all experiments).

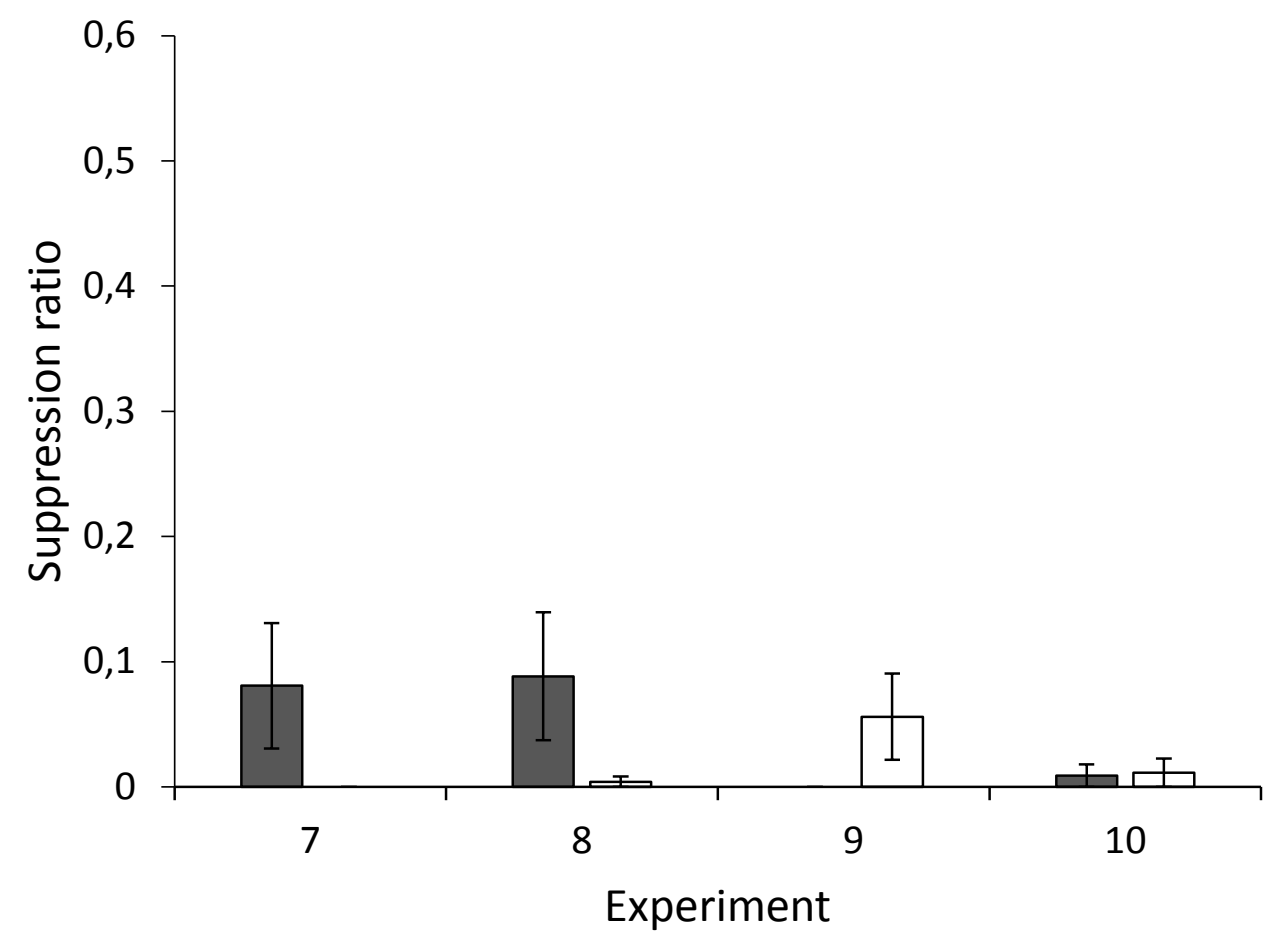

Figure 4. Mean suppression ratio at test across the first three presentations of $\mathrm{X}$ for experimental and control groups, for Experiments 7 to 10. Error bars represent standard errors of the means. Mean and SD of the control group in Experiments 7 were both zero.

SERIES 4 (EXPERIMENTS 11-14): FAILURE TO OBTAIN BLOCKING IN APPETITIVE CONDITIONING IN SPRAGUE-DAWLEY RATS

Method

\section{General overview}

In four experiments, female rats were trained in a Pavlovian approach procedure, in which magazine entries during stimulus presentation were measured as an index of food expectancy. The procedure of these experiments was again similar to previous reported studies that have demonstrated a blocking effect (Holland, 1999; Taylor et al., 2008) (see Table A4 in Appendix A for a 
comparison with those previous studies and Table B1 and C1 in Appendix B and C, respectively, for an overview of the stimuli and procedure used in this series).

\section{Subjects}

Subjects were experimentally naïve, female Sprague-Dawley rats obtained from Janvier (Le Genest-Saint-Isle, France). The animals were housed in a vivarium maintained on a 12-h day-night cycle. The animals were allowed free access to water, whereas food availability was limited to minimum $12 \mathrm{~g}$ per rat per day following a progressive deprivation schedule initiated one week prior to the start of the study.

Experiments 11 and 12 . Subjects were 12 ( $\mathrm{ns}=6$ ) female rats with body weights ranging from 206 to $268 \mathrm{~g}$ for Experiment 11 and from 212 to $248 \mathrm{~g}$ for Experiment 12, before deprivation. Animals were housed in groups of four.

Experiments 13 and 14 . Subjects were 24 (ns $=12$ ) female rats with body weights ranging from 160 to $227 \mathrm{~g}$ before deprivation for Experiment 13 and from 185 to $218 \mathrm{~g}$ for Experiment 14 . Animals were housed in groups of six. The subjects in these experiments were part of a larger experiment involving four groups. Animals in the other two groups were given subadditive pretraining before the start of blocking training, which has been shown to diminish blocking (Beckers et al., 2006), and were therefore not included in the analyses.

\section{Apparatus}

Twelve standard operant chambers ( $34 \mathrm{~cm}$ length $\times 33 \mathrm{~cm}$ width $\times 33 \mathrm{~cm}$ height; Coulbourn Instruments, Allentown, PA, USA) housed in sound- and light-resistant cubicles (Coulbourn Instruments, Allentown, PA, USA) were used. All chambers had metal ceilings and side walls and clear Plexiglas front and back walls. The floors were constructed of stainless steel grids $(0.5 \mathrm{~cm}$ in diameter). Each chamber was equipped with a food dispenser that could deliver 45-mg sucrose pellets (TestDiet, St. Louis, MO) into a recess, which could be illuminated by a white light. Pellet delivery was indicated by the illumination of the recess for $0.5 \mathrm{~s}$. A photocell sensor placed in the 
recess was able to detect head entries. The enclosure was dimly illuminated by a house light. A light bulb, mounted on the opposite wall of the house light, was used to deliver a flashing light ( $0.1 \mathrm{~s}$ on/ $0.1 \mathrm{~s}$ off). The house light was turned off when the other light was flashing. Three speakers were mounted on two different interior walls. One was used to deliver a $1000-\mathrm{Hz}$ tone, a $7000-\mathrm{Hz}$ tone or a $11000-\mathrm{Hz}$ tone. The second one was also used to deliver a $7000-\mathrm{Hz}$ tone. The third one delivered a white noise. A clicker was able to deliver a clicking sound ( 5 clicks/s). All CSs were $10 \mathrm{~s}$ in duration. For an overview of the stimuli used in each experiment, see Appendix B, Table B1.

Experiment 11. The clicker (72 dBC), the white noise ( $83 \mathrm{dBC})$, and a $1000-\mathrm{Hz}$ tone $(90 \mathrm{dBC})$ served as A, B and X, semi-counterbalanced using the Latin square method.

Experiment 12. A pulsing $1000-\mathrm{Hz}$ tone $(0.2 \mathrm{~s}$ on/ $0.2 \mathrm{~s} \mathrm{off,} 73 \mathrm{dBC}$ ) and a pulsing $7000-\mathrm{Hz}$ tone $(0.5 \mathrm{~s}$ on $/ 0.1 \mathrm{~s}$ off, $68 \mathrm{dBC}$ ), both delivered through the same speaker, served as $A$ and $B$, counterbalanced. The clicker $(72 \mathrm{dBC}$ ) served as stimulus $\mathrm{X}$.

Experiment 13. The buzzer ( $77 \mathrm{dBC})$ and the flashing light were used as $C$ and $D$, counterbalanced. A pulsing $1000-\mathrm{Hz}$ tone $(0.2 \mathrm{~s}$ on/ $0.2 \mathrm{~s}$ off, $73 \mathrm{dBC})$ and a pulsing $7000-\mathrm{Hz}$ tone $(0.5$ $\mathrm{s}$ on/ $0.1 \mathrm{~s}$ off, $68 \mathrm{dBC}$ ), emerging from different speakers, served as $A$ and $B$, counterbalanced. The clicker (72 dBC) served as stimulus $X$.

Experiment 14. The buzzer and the flashing light were used as $C$ and $D$, counterbalanced. $A$ $1000-\mathrm{Hz}$ tone $(73 \mathrm{dBC})$ and the clicker $(72 \mathrm{dBC})$ served as $A$ and $B$, counterbalanced. The white noise (69 $\mathrm{dBC}$ ) served as stimulus $\mathrm{X}$ and a $11000-\mathrm{Hz}$ tone $(61 \mathrm{dBC})$ served as stimulus $\mathrm{T}$.

\section{Procedure}

The experiments in this series were run in a rat lab at KU Leuven. Each training session was 60 min long. Appendix C, Table C1 provides an overview of the number of training days in each training phase for each experiment.

Magazine training. All rats initially received 30 sucrose pellets during a 40-min session. 
Pretraining. In Experiment 13 and 14, animals were exposed daily to 14 pairings of $C$ with the US and seven pairing of D with the US, with the stimulus ending in delivery of a food pellet. No pretraining was given in Experiments 11 and 12.

Phase 1: Elemental training. In Experiments 11 to 13, animals in the experimental group were exposed daily to 20 pairings of A with the US, with the stimulus ending in delivery of two food pellets. Animals in the control group received similar pairings of B with the US. In Experiment 14, animals in the experimental group were exposed daily to 16 pairings of A with the US and 4 unreinforced presentations of stimulus T. The animals in the control group received 16 pairings of B with the US as well as 4 unreinforced presentations of stimulus T. The number of elemental training days differed for each experiment (see Appendix C, Table C1).

Phase 2: Compound training. During a single compound training session, all animals received 20 pairings of the $A X$ compound with the US.

Test. All animals were tested on X, which was presented 10 (Experiments 11 to 13, session duration $35 \mathrm{~min}$ ) or 20 (Experiment 14, session duration $60 \mathrm{~min}$ ) times.

\section{Results}

An elevation score for the number of head entries per trial was calculated as the mean number of head entries during each presentation of $\mathrm{X}$ minus the mean number of head entries during the 10-s period immediately preceding the CS. Figure 5 depicts the mean elevation score across the first ten trials, for Experiments 11 to 14. The difference between the elevation score for the experimental group and the control group in Experiments 11 to 13 was numerically in line with a blocking effect; however, it failed to reach significance [smallest $p=0.19$ (one-tailed)]. However, it is clear from Figure 5 that not a hint of a blocking effect was observed in Experiment 14 (see Appendix D, Table D1 for detailed statistics). To ascertain that the results were not due to differences in preCS responding between groups, we compared preCS responding before the first presentation of $X$ between groups for all experiments. No baseline differences were observed in any of the four experiments (see Appendix D, Table D2 for detailed statistics). Power analyses on the basis of the 
effect sizes reported in the most similar published blocking studies (see Appendix E for details) suggest that the absence of a blocking effect was not due to a lack of power (estimated power $=.70$ for Experiments 11 and 12 and $>0.90$ for Experiment 13 and 14).

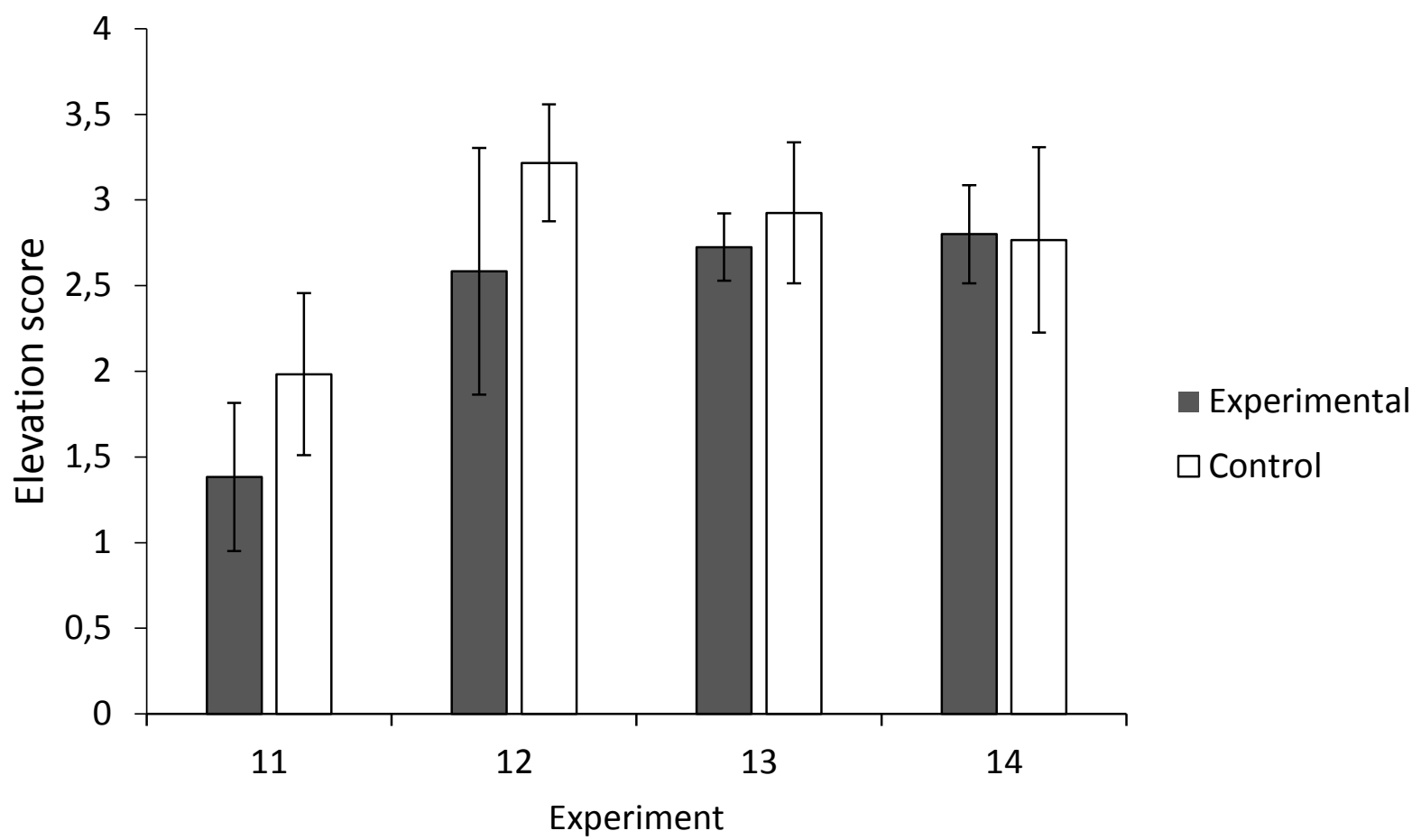

Figure 5. Mean elevation score across the first ten presentations of $\mathrm{X}$ for experimental and control groups, for Experiments 11 to 14. Error bars represent standard errors of the means.

\section{SERIES 5 (EXPERIMENT 15): FAILURE TO OBTAIN BLOCKING IN APPETITIVE} CONDITIONING IN CRL:CD RATS IN A PRE-REGISTERED EXACT REPLICATION

Method

\section{General overview}

In light of our consistent failure to obtain blocking using a variety of procedures that were inspired by but not fully identical to previous reports, in a final experiment we conducted a highly powered exact replication of a blocking effect reported in the literature. In consideration of the restrictions imposed by the equipment we had available and the strains of rats readily available to us, we decided to replicate Conditions 1 and 2 (a regular blocking condition and its control) of Taylor and 
colleagues (2008, Experiment 3). In this experiment, male rats were trained in a Pavlovian approach procedure, in which magazine entries during stimulus presentation were measured as an index of food expectancy. The protocol was screened and approved by the acting editor of the journal prior to the start of the study, and pre-registered online at https://osf.io/f3uxm/?view only=fe87f3cd67234810a5dc25e7cdb5377f. More detailed information about the procedure is also provided there; see Table B1 and C1 in Appendix B and C, respectively, for an overview of the stimuli and procedure used in this experiment. The sample size of the study was determined such as to yield an estimated power of more than .90 based on the effect size reported by Taylor at al. (2008) (see Appendix E for details).

\section{Subjects}

Subjects were $60(n s=30)$ experimentally naïve, male $C R L: C D$ rats obtained from Charles River Laboratories (Saint Germain Nuelles, France). The animals were housed in a vivarium maintained on a 12-h day-night cycle. The animals were allowed free access to water, whereas food availability was limited to minimum $1 \mathrm{hr}$ per day following a progressive deprivation schedule initiated one week prior to the start of the study.

\section{Apparatus}

The same twelve operant chambers and cubicles were used as for the previous series. Each chamber was equipped with a food dispenser that could deliver two 45-mg non-purified grain-based pellets (TestDiet, St. Louis, MO) into a recess. A photocell sensor placed in the recess was able to detect head entries. The enclosure was dimly illuminated by a red house light. A light bulb, mounted above and to the left of the recess, was used to present stimulus X. Two speakers, mounted on two different interior walls, were used to present a $1000-\mathrm{Hz}$ tone $(80 \mathrm{dbC})$ and a white noise $(80 \mathrm{dBC})$, which served as stimuli A and B, counterbalanced. All CSs were $12 \mathrm{~s}$ in duration. For an overview of the stimuli used, see Appendix B, Table B1. 


\section{Procedure}

The experiments in this series were run in a rat lab at KU Leuven. Each training session was 35 min long. Appendix C, Table C1 provides an overview of the number of training days in each training phase.

Magazine training. Reinforcement was delivered on a variable time 45-s schedule for three days.

Phase 1: Elemental training. During the 15 days of elemental training, all animals in the experimental group were exposed daily to 10 pairings of A with the US, with the stimulus ending in delivery of two food pellets. Animals in the control group received similar pairings of B with the US.

Phase 2: Compound training. During the five compound training days, all animals received 10 pairings of the $\mathrm{AX}$ compound with the US, with similar specifics as for elemental training.

Test. Three test sessions were held on successive days, with X presented on the first day, A on the second and B on the third day. Each test session included 10 trials, on each of which the stimulus to be tested was presented without reinforcement for $12 \mathrm{sec}$. After conducting those test sessions, we decided to add a fourth day of testing, which was not conducted by Taylor et al. (2008) and not included in our preregistered replication protocol, to evaluate whether a difference in responding might emerge over further testing. During this final test session $\mathrm{X}$ was presented using the same parameters as for the previous test sessions.

Acquisition $X$. Given the lack of conditioned responding to $X$ during test, we decided to evaluate whether $X$ was able to support conditioning at all. All animals received 10 pairings of $X$ with the US, with similar parameters as for the elemental training of $A$ and $B$. This additional acquisition phase was also not conducted by Taylor et al. (2008) and not included in our preregistered replication protocol.

Results

Mean elevation scores per trial were calculated for $\mathrm{X}, \mathrm{A}$ and $\mathrm{B}$ as the mean number of head entries during each presentation of the $\mathrm{CS}(\mathrm{X}, \mathrm{A}$ or $\mathrm{B})$ minus the mean number of head entries during 
the 12 -s period immediately preceding the CS. Figure 6 depicts the mean elevation scores across the ten presentations of each CS during the three test sessions for experimental and control groups. It is clear from Figure 6 that not a hint of a blocking effect was observed, despite the fact that, as expected and in line with Taylor et al. (2008), elevation scores to A were higher in the experimental group than in the control group and elevation scores to B were lower in the experimental group than the control group (see Appendix D, Table D1 for detailed statistics). To ascertain that the results were not due to differences in preCS responding between groups, we compared preCS responding before the first presentation of $X, A$ and $B$ between groups. No baseline differences were observed in any of the three test sessions (see Appendix D, Table D2 for detailed statistics). Whereas with a Cohen's d of 0.81 , the blocking effect reported by Taylor et al. (2008) was somewhat smaller in size than that of many other reported blocking effects, the much larger than average sample size ensured a power of over .90 to detect such effect (see Appendix E for details).

We did not observe a significant difference between the experimental and control group in the additional test session for $X$ either $\left[M_{\text {experimental }}=-0.00, S D_{\text {experimental }}=0.19, M_{\text {control }}=-0.00, S_{\text {control }}\right.$ $\left.=0.14, t(58)<0.01, p=0.50, d<0.01, B F_{10}=0.26\right]$.

In light of the surprising lack of blocking, we ran an additional training session, which was not included in our preregistered replication protocol, to check whether animals did notice $\mathrm{X}$ and were able to learn about $X$. After one day of acquisition with $X$, mean number of head entries during $X(M=2.48 ; S D=1.44)$ was higher than mean number of head entries during the preX interval $(M=$ 1.93; $S D=1.28)\left[t(59)=-3.76, p<.01, d=-0.49, B F_{10}=62\right]$. Mean elevation score across all trials did not differ between the experimental $(M=0.58 ; S D=1.20)$ and control group $(M=0.51 ; S D=1.06)$ $\left[t(58)=0.24, p=0.81, d=0.06, B F_{10}=0.27\right]$.

Altogether, the results suggest that $\mathrm{X}$, although perfectly capable of supporting conditioning, was overshadowed to the same extent by $A$ and $B$ (despite $A$ eliciting more responding in the blocking than in the control group). Overshadowing is the observation that conditioned responding to an elementally tested CS (i.e., the overshadowed cue; in this case X) is weaker when it was trained 
in compound with another CS (i.e., the overshadowing cue; in this case A), as compared to when it was trained elementally (Pavlov, 1927, P. 141). So, although we observed reduced responding to X this was not a consequence of the A+ training provided to the animals in the experimental group and hence, not a true blocking effect.

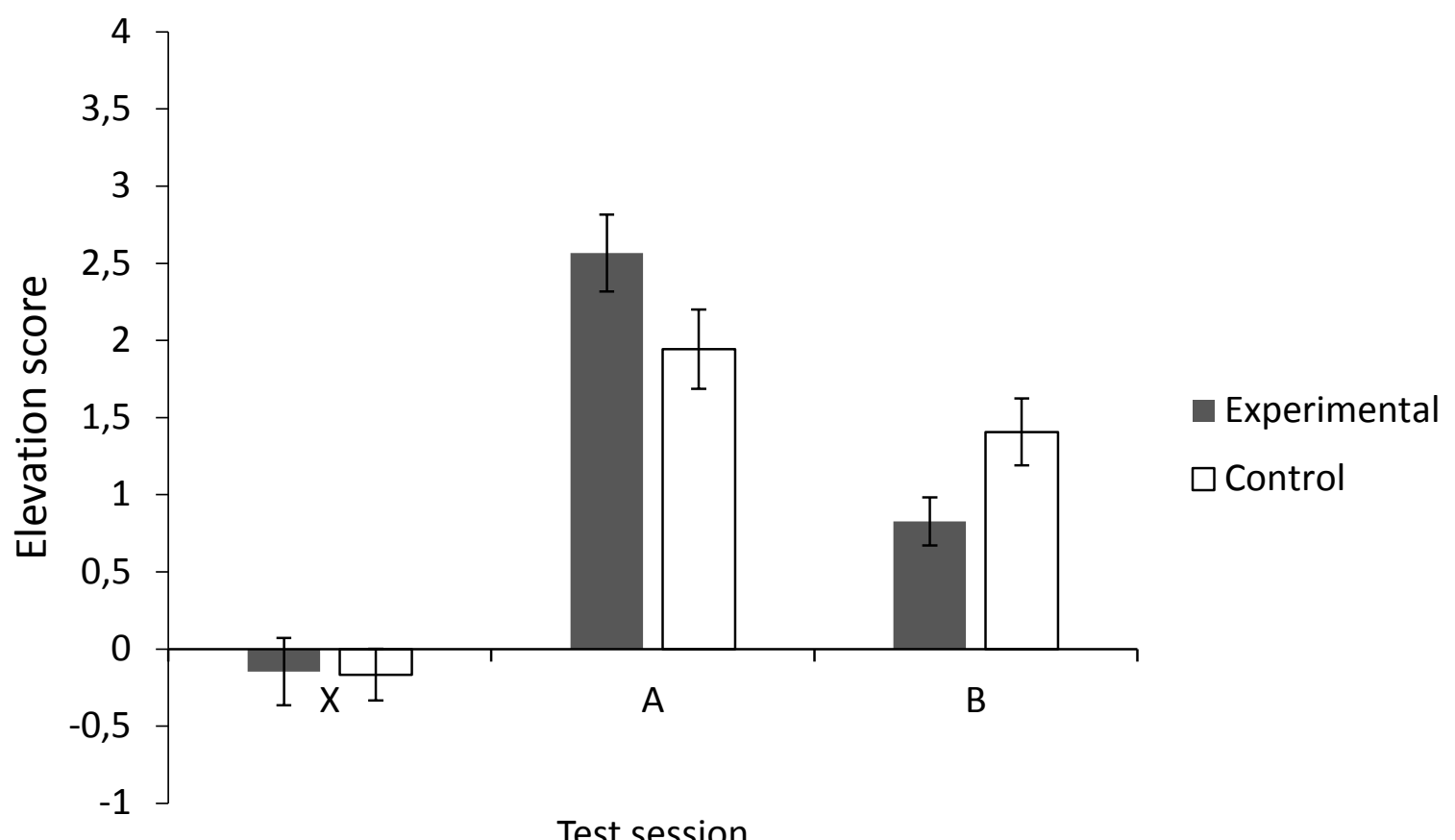

Figure 6. Mean elevation scores across the ten presentations of each CS during the three test sessions for experimental and control groups. Error bars represent standard errors of the means.

\section{BAYESIAN ANALYSIS}

Frequentist statistical techniques do not allow to infer the absence of an effect (Wagenmakers, 2007), making it difficult to draw conclusions regarding the lack of blocking from the analyses presented so far. In Bayesian hypothesis testing, however, a Bayes Factor (BF) can be calculated that quantifies the strength of the relative statistical evidence for two rivaling hypotheses. A BF quantifies the relative probability of the data under, e.g., the null versus the alternative hypothesis (Dienes, 2011; Gallistel, 2009; Morey, 2015; Rouder, Speckman, Sun, Morey, \& Iverson, 2009). If a BF of about 1 is obtained, there is no evidence in favor of either one of the hypotheses; the more the BF exceeds one, the more evidence is obtained for the data under the 
hypothesis in the nominator, compared to the hypothesis in the denominator. The reverse holds for BFs below 1. According to Jeffreys (1961), BFs above three can be regarded to provide substantial evidence in favor of the hypothesis that is in the nominator (or, conversely, values below 0.33 provide substantial evidence for the hypothesis in the denominator). In order to calculate the BF one needs to specify a prior distribution of the probability of the different effect sizes under each hypothesis before considering the data (Dienes, 2011).

We calculated $\mathrm{BF}_{10}$ (i.e. the probability of the data given the null hypothesis divided by the probability of the data given the alternative hypothesis) for all experiments reported in the current paper using JAPS 0.7.1 (Love et al., 2015) and assuming a default prior distribution (Ly, Verhagen, \& Wagenmakers, in press) ${ }^{2}$. None of the experiments yielded a $\mathrm{BF}_{10}$ above three (see Appendix $\mathrm{D}$, Table D1 for detailed statistics), indicating that none of the experiments provided substantial evidence for the alternative hypothesis - that is for the presence of a blocking effect. Four experiments (Experiments 3, 6, 9 and 15) provided substantial evidence for the absence of a blocking effect $\left(\mathrm{BF}_{10}\right.$ below 0.33$)$. The remaining experiments yielded at best anecdotal evidence for either of the hypotheses, with BFs between 0.33 and 3 .

To evaluate the overall evidence provided by the data, we next computed a meta-analytic BF (MABF) using the BayesFactor package (Morey \& Rouder, 2015) in R (R Core Team, 2015). A MABF can be interpreted in much the same way as a regular $\mathrm{BF}$, that is it expresses the relative probability of observing the data under the two competing hypotheses after observing the data across all the reported experiments (see Rouder, \& Morey, 2011 for more details on MABFs). The computed

\footnotetext{
${ }^{2}$ We performed robustness analyses to evaluate to what extent our findings were influenced by our
} choice of a default prior distribution on the effect size (Wagenmakers, Wetzels, Borsboom, \& van der Maas, 2011, Online Appendix). The results of those analyses are available on https://osf.io/fcwnr/?view only=754693fa2907497a9ad8013a63813781. With wider priors (i.e. assigning a higher prior probability to effect sizes further removed from zero), the relative evidence in favor of the null hypothesis further increased. 
$\mathrm{MABF}_{10}$ was equal to 0.13 , providing substantial evidence for the null hypothesis over the alternative hypothesis. Of importance, the MABF provided stronger support for the null hypothesis than any of the individual experiments.

One might argue that the observation of blocking in Experiments 2, 3 and 15 was hampered by a floor effect - if the control group is hardly responding to $\mathrm{X}$, lower responding in the experimental group cannot be expected. To exclude that the results of the Bayesian meta-analysis were driven mainly by the latter experiments, we repeated the Bayesian meta-analysis without them. $A \mathrm{MABF}_{10}$ of 0.16 was obtained, indicating that even when excluding the potential influence of floor effects, we find substantial evidence in favor of the null hypothesis.

One might similarly argue that the observation of blocking in Experiments 1 and 6 to 10 was hampered by a ceiling effect. It is not clear that that is a valid argument, because a strong response in the control group is to be expected (animals in this group are assumed to learn about X) and the stronger the response in the control group, the more room there should be for observing a reduction in that response in the experimental group. The observation that also in the experimental group conditioned responding is very strong in those experiments suggests that the animals learned about $\mathrm{X}$ in those groups as well, which - by its very definition - constitutes the absence of a blocking effect. Nevertheless, we also conducted a meta-analysis that included Experiments 4, 5 and 11-14 only (thereby omitting all experiments that could possibly suffer from floor or ceiling effects) and still obtained substantial evidence in favor of the null hypothesis $\left(\mathrm{MABF}_{10}\right.$ of 0.20$)$.

\section{GENERAL DISCUSSION}

The purpose of the series of experiments reported here was to establish a blocking procedure that would produce robust effects and could thus serve as a starting point to investigate the cognitive processes involved in blocking. The abundance of publications reporting a blocking effect and the importance attributed to it, suggest that it is a robust phenomenon. Yet in fifteen experiments in which we used procedures similar or identical to previously published studies that 
demonstrated a blocking effect, not a single significant blocking effect was obtained using one-tailed tests and a rejection criterion of $p<.05$. Power analyses moreover indicate that it is unlikely that the consistent absence of a blocking effect can be attributed to a lack of power (see Appendix E for details). Even when we replicated a published report in great detail, no indication of a blocking effect was observed, despite an estimated power of well above .90 . A trend towards significance $(p<$ .10) was observed in two experiments (Experiments 5 and 8), but Bayesian analysis suggests that even in those studies, evidence for blocking was no more than anecdotal, and in subsequent studies, we were never able to replicate those near-significant effects. For four experiments (Experiments 3 , 6, 9 and 15), Bayesian analysis provided substantial evidence for the null hypothesis. Moreover, a meta-analytic BF provided substantial evidence in favor of the null hypothesis across all 15 experiments.

Importantly, the failures to generate a blocking effect reported in the current paper were not limited to one specific lab or experimental set-up: the first series was run in a mice lab at KU Leuven, the second series was run in a rat lab at the University of California, Los Angeles, and the third, fourth and fifth series were run in a rat lab at KU Leuven. Nor were they limited to one specific procedure: We tried conditioned suppression of nose poking and lever pressing as well as an appetitive procedure. Although we are not the first to report problems in obtaining a blocking effect (Taylor et al., 2008; see further), the current report is by far the most extensive series of failures to find blocking in the literature. While from the abundance of successful studies published, it appears undisputable that blocking is a genuine and important phenomenon, our results do raise doubts regarding the canonical nature of the blocking effect. The current series of failures suggests that blocking is a highly parameter-dependent phenomenon. This is especially highlighted by the fact that we failed to replicate the near-significant effects of Experiments 5 and 8 in highly similar followup studies. In a final attempt to obtain blocking (Experiment 15), we followed a published report to the letter, yet a blocking effect was once again not observed. Admittedly, the protocol employed in this experiment might differ from the one by Taylor and colleagues in parameters that were not 
mentioned in their report because they were deemed irrelevant. Yet such an interpretation would imply not only that blocking is a highly parameter-dependent phenomenon, but also that we lack knowledge on which parameters are significant and deserve reporting. In what follows, we will discuss in detail the validity of our results and the implications of our findings for psychological science in general and the associative learning field in particular.

It is one thing to observe that we failed to find evidence for a blocking effect across a series of 15 experiments, but quite another to determine what the cause for those failures might be. Despite the fact that we adhered to protocols and procedures described in previous reports in which a blocking effect was demonstrated, we may have somehow failed to fulfill crucial boundary conditions. Theoretical accounts for blocking may offer clues regarding potential boundary conditions. Many association-formation models of associative learning postulate that surprise is essential for learning to occur (e.g. Mackintosh, 1975; Pearce \& Hall, 1980; Rescorla \& Wagner, 1972; see also Introduction). If the presence or absence of a US on a given trial is surprising, the associative strength of the stimuli presented on that trial will change (increase if a US is surprisingly present, decrease if a US is surprisingly absent). Associative strength in turn determines the strength of the CR (possibly in combination with other factors) (e.g. Rescorla, 2001). Therefore, in order for X to acquire less associative strength in the experimental group than in the control group and blocking to be observed, two factors are crucial according to those models: (1) the US should not be surprising at the beginning of the compound phase in the experimental group, because only then will $X$ be prevented from gaining associative strength, and (2) the US should be surprising at the beginning of the compound phase in the control group, because only then will $\mathrm{X}$ be able to gain associative strength. In order for those two conditions to be met, (1) the blocking stimulus A should gain significant associative strength over the course of elemental training (otherwise the first condition will not be met) and (2) generalization of associative strength from B to A should be limited such that the US is not fully predicted on the first presentations of AX in the control group, 
allowing $\mathrm{X}$ (and $\mathrm{A}$ ) to gain more associative strength during compound training in the control group than in the experimental group.

To check whether those boundary conditions were met in our experiments, we analyzed the training data of Experiments 4 and 10 to 15 (in the other experiments, Pavlovian training was performed offline, so training data are not available). The available data from the elemental phase show that conditioned responding to the elemental stimulus (A or B; expressed as suppression ratios for Experiments 4 and 10 and elevation scores for Experiments 11 to 15) was significantly higher by the end of the phase than at the start (see Appendix F, Table F1 for detailed statistics) ${ }^{3}$. Moreover, responding seemed to be at asymptote at the end of elemental training, indicated by 1) the absence of a linear trend over trials on the last day of elemental training and 2) the absence of a difference in conditioned responding between the first and last trial of the last day of elemental training (see Appendix G, Tables G1 and G2 for detailed statistics). The procedures used in experiments that were conducted offline were similar to the procedures of one or more of the other experiments. Therefore, we can be relatively confident that the first hypothetical boundary condition for generating a blocking effect that can be derived from theoretical models of associative learning (i.e. that the US was predicted by the blocking stimulus A at the end of elemental phase) was met ${ }^{4}$. To check whether the second hypothetical boundary condition was met, one can look at the difference in responding between the experimental and control condition on the first AX presentation of the compound phase. The rationale behind this comparison is that if there is more responding to the first AX presentation in the experimental group than in the control group, there cannot have been full generalization from $B$ to $A$, thus leaving more room for $X$ to gain associative strength on $A X$ trials

\footnotetext{
${ }^{3}$ For Experiment 4 only session level data were available. So, rather than comparing CRs to the first
} and the last presentation of $A, C R s$ during the first session were compared with CRs during the last session.

${ }^{4}$ In Exp. 4., suppression ratios did not exceed 0.15 from the second day onwards. This suggests that, although elemental training was shorter in Exp. 1-3, the blocking cue A would have asymptotically predicted the presence of the US at the end of elemental training in those experiments as well. 
in the control group than in the experimental group. Of course, this is an imperfect test of generalization, because responding to $\mathrm{AX}$ in the control group can be influenced by a number of factors other than conditioned generalization, such as an orienting response to $\mathrm{AX}$ ( $\mathrm{AX}$ is more novel in the control group than in the experimental group). Arguably, then, this test might overestimate the degree of generalization from $B$ to $A$. A better alternative would be to compare responding to $A$ and B directly in both groups, as we did in Experiment 15. In this experiment, experimental and control animals differed in responding to $A$ (higher responding in the experimental than in the control group) as well as B (higher responding in the control than in the experimental group), yet no difference in conditioned responding to the first AX presentation was observed between groups. That observation supports the idea that comparing responding to the first AX presentation might overestimate generalization. Moreover, at least in Experiment 15, we have strong evidence against a generalization account of our results.

The question remains whether B to A generalization could account for the lack of blocking in the other experiments. Two observations are relevant for this question. First, across Experiments 10 to 15 conditioned responding (expressed as suppression ratios for Experiment 10 and elevation scores for Experiments 11 to 15) on the first trial of the compound phase was numerically higher in the experimental group than in the control group in all but one of the experiments (Experiment 12), although the differences between the groups were never significant (see Table $\mathrm{H} 1$, Appendix $\mathrm{H}$ for statistical details; relevant data were not available for the other experiments). Note, however, that this trend was observed even though responding on the first $A X$ trial probably overestimates generalization. Overall, those results suggest, at the very least, that generalization was not complete. Second, conditioned responding to $X$ was substantial. If generalization from $B$ to $A$ was strong in some of our experiments, the absence of a blocking effect in those experiments might be the result of $X$ not being able to gain associative strength in the control group (because $X$ would be blocked by $\mathrm{A}$ as the result of generalization from preceding $\mathrm{B}+$ training). In that case, low conditioned responding to $\mathrm{X}$ should be observed at test in both groups because $\mathrm{A}$ would block 
learning of the X-US relation in both conditions. However, across Experiments 10 to 15 conditioned responding (expressed as suppression ratios for Experiment 10 and elevation scores for Experiments 11 to 15$)$ for the first presentation of $X$ at test was never significantly less than conditioned responding to the last presentation of A for either of the groups (see Table I1, Appendix I for statistical details; relevant data were not available for the other experiments). In fact, conditioned responding to $X$ was often even numerically higher than final conditioned responding to $A$ (exceptions here are Experiments 12 and 15). Hence, whereas a generalization account would predict blocking due to an absence of X-US learning in both the control and blocking groups, we observed strong evidence for X-US learning in both groups. So, all in all, it seems unlikely that the lack of blocking that we observed was due to excessive generalization from B to A. Moreover, given that we observed a difference in responding to both $A$ and $B$ between groups in Experiment 15, we can be confident that at least in this experiment the failure to observe blocking was not a consequence of excessive generalization from B to $A$.

It is important to note that the two potential boundary conditions discussed above follow naturally from the assumptions entailed by many association-formation models. However, given that most published reports of a blocking effect do not contain training data, there is no way of knowing whether those boundary conditions were actually met in previous research and thus whether there is empirical evidence for those boundary conditions. For instance, it is not clear from earlier research whether a difference in conditioned responding to AX between the experimental and control groups at the start of training is necessary or even helpful to observe blocking. It would be important to establish those (or any other) boundary conditions empirically because they are not a theoretical necessity. That is, some theoretical accounts of the blocking effect (e.g., Beckers et al., 2006; Miller \& Matzel, 1988) do not yield the same boundary conditions. In general, little has been said in the literature about boundary conditions for blocking. Our results are important if only for that reason, because they clearly suggest that the blocking effect is indeed dependent on (a variety of) boundary conditions, the exact nature of which is yet to be determined. 
The question remains then how to reconcile the relative abundance of demonstrations of blocking in the literature with our consistent failure to observe the effect under various conditions. We believe that at least part of that conundrum may be linked to the use of suboptimal control conditions in a number of published reports, that is, control conditions that do not allow to conclude that the observed between-groups difference is actually a true blocking effect. We are not the first to raise this issue (Arcediano, Escobar, \& Matute, 2001). Kamin, and others after him, simply omitted elemental training altogether in the control group (e.g. Allen, Padilla, Myers, \& Gluck, 2002; Feldman, 1975; Kamin, 1969; Solomon, 1977). However, the difference between groups in exposure to the US in such a design is highly problematic; weaker conditioned responding to $\mathrm{X}$ in the experimental group than in the control group can then simply reflect differences in habituation to the US or any other sort of mere exposure effect (Prados et al., 2013). To avoid this problem, researchers have been using unsignalled US presentations in the control group, in different ways (random presentations of $A$ and the US during the elemental phase, backward $A B+$ / $A+$ training or simply replacing the elemental training by presentations of the US; e.g. Holland \& Gallagher, 1993; Parker, 1986; Wagner, 1969). The problem is that responding during test has been proven to be enhanced in such control groups relative to conditions that receive compound $A X+$ training only, perhaps due to contextual reinforcement during training (Taylor et al., 2008). Other researchers have replaced elemental training by discrimination training (A+/B- in the experimental group and B+/A- in the control group; e.g. Dopson, Pearce, \& Haselgrove, 2009). However, such designs empirically conflate blocking and reduced overshadowing: higher responding to $\mathrm{X}$ in the control group than in the experimental group may reflect enhanced responding in the former rather than reduced responding in the latter, relative to mere compound training. That is, a reduction of overshadowing may be observed if the overshadowing cue is preexposed without reinforcement (e.g. De Houwer, Beckers, \& Glautier, 2002). In a within-subjects variant of this paradigm, A+/Btraining is followed by AX+/BY+ training (e.g. Rescorla, 1999; Waelti, Dickinson, \& Schultz, 2001). Here as well, the observation of a difference between $\mathrm{X}$ and $\mathrm{Y}$ can be the result of a true blocking 
effect (reduced responding to $X$ due to $A+$ training), a reduction of overshadowing (heightened responding to $\mathrm{Y}$ due to $\mathrm{B}$ - training), or a combination of both. Of importance, existing theories of learning may be differentially compatible with each of those phenomena. For instance, the RescorlaWagner model readily predicts true blocking but has no mechanism to account for reduced overshadowing. Therefore, if apparent blocking effects in the literature are driven in whole or in part by the use of suboptimal control groups, it may affect how well they support various theories of learning.

The control procedure used in the current experiments $(\mathrm{B}+$ training followed by $\mathrm{AX}+$ training) equates experience with the US between groups and avoids the possibility that betweengroups differences reflect reduced overshadowing rather than true blocking. It has been claimed, however, that an apparent blocking effect in such a procedure might reflect heightened responding to $\mathrm{X}$ in the control group rather than diminished responding to $\mathrm{X}$ in the blocking group, on the assumption that more generalization to $X$ takes place from $n B$ pairings, with $n$ the number of elemental training trials, and $\mathrm{m} A$ pairings, with $\mathrm{m}$ the number of compound training trials, (as the control group receives) than from $n+m$ A pairings (Blaser et al., 2006). This possibility was refuted when Taylor and colleagues (2008) observed equal responding to X in an X-absent 'blocking' group (which received mere elemental pairings of $A$ with the US) compared to an X-absent 'control' group (which first received elemental pairings of $B$ with the US and then elemental pairings of $A$ with the US). In conclusion, the control procedure used in the current experiments is to be regarded as the most appropriate of the control groups commonly used in blocking experiments (Arcediano, Escobar, \& Matute, 2001; Taylor et al., 2008).

To reiterate, we do not want to dispute that the blocking effect exists. As indicated in the introduction, some of us had performed or been involved with successful blocking studies in rodents before embarking on the present series of failures. The full set of all the blocking experiments in rodents that any of the authors of the current paper have ever executed, supervised or otherwise been involved with consists of the experiments reported here plus the experiments reported by 
Beckers et al. (2006) and Wheeler et al. (2008). This set can therefore be taken as an unbiased dataset, devoid of publication bias. If we repeat the Bayesian meta-analysis reported above but now including the 11 blocking effects contained in those earlier reports (excluding a few experimental and control groups that were specifically designed not to yield a blocking effect, such as the subadditive pretraining groups in Beckers et al., 2006, Experiment 1; for details, see Table J1 in Appendix J), we obtain a $\mathrm{MABF}_{10}>100$, which clearly indicates that blocking is a real phenomenon (see https://osf.io/fcwnr/?view only=754693fa2907497a9ad8013a63813781 for more details).

The results presented here do suggest that a true blocking effect is more difficult to obtain than one might assume from the literature and that we lack insight into its boundary conditions. An imprecise use of the term 'blocking', which conflates a number of other effects, perhaps in combination with some degree of publication bias may have led to an overestimation of how robust and reliable true blocking is and an underestimation of the importance of potential boundary conditions for its observation. Indeed, given the canonical nature of the blocking effect in textbooks of learning, many researchers may have been dissuaded from publishing failures to obtain blocking. Some may have been dissuaded from pursuing the effect upon failure. Others may have continued until they obtained a robust and reliable effect, but have likely neglected to systematically examine and document relevant variables and boundary conditions for obtaining the effect, in light of the general view that the blocking effect is not subject to such conditions. As a result, we may be left with a biased perspective regarding the universality of blocking. This situation is perhaps not much different from what appears to be the case for other seemingly established phenomena in the psychological literature. Indeed, we believe that blocking is not unique in being over promoted. Other phenomona within and beyond the domain of associative learning may be more elusive than their status suggests as well. Consider, as an example, social priming effects, that is, observations that activation of relevant stereotypes, attitudes, traits and goals in one context can influence the behavior in another context unconsciously. While evidence has been reported for a variety of such effects (e.g. individuals can be implicitly primed to walk faster or slower (e.g. Bargh, Chen, \& 
Burrows, 1996) or to behave more or less intelligently (Dijksterhuis \& Knippenberg, 1998)), some researchers have recently started to question the mere existence of social priming (e.g. Shanks et al., 2013). Rather than attempting to address this issue as a yes-or-no question, other researchers have started to focus on the conditions under which a social priming effect can be observed and the mechanisms that mediate its occurrence (e.g. Bargh, 2006; Doyen, Klein, Pichon, \& Cleeremans, 2012; Gomes \& McCullough, 2015; Sharrif \& Norenzayan, 2015), an avenue, we argue, that would be fruitful for the blocking effect as well.

In closing, we have no doubt that true blocking exists, that many existing reports of the effect are genuine, and that many of those reports may be replicable in the hands of the very researchers that obtained them. However, the misuse of the term blocking and publication bias might have mislead us in our perception of how robust, reliable and general of a phenomenon blocking is. Our results suggest that several boundary conditions might need to be fulfilled in order to observe blocking. We therefore argue that blocking, rather than being a touchstone for our theories of elementary learning, should be the subject of further investigation. Some studies have begun to explore procedural variables that are important for blocking to occur (Arcediano, Escobar, \& Miller, 2004; Blaser et al., 2006; Feldman, 1975; Janisiewicz \& Baxter, 2003; LoLordo, Jacobs, \& Foree, 1982; Pineño et al., 2005; Taylor et al., 2008). However, it is clear that many moderators are unknown, as the current series of failures illustrates. In tandem with a functional approach that is directed at uncovering the moderators, further research may aim to decipher the dynamic cognitive processes that might underlie blocking (Boddez, Haesen, Baeyens, \& Beckers, 2014). Through a combined increase in procedural and process level knowledge (see De Houwer, 2011, for a theoretical discussion on the benefits of combining functional and cognitive approaches to psychology), blocking will perhaps become a less central effect in theories of learning, but hopefully also a less elusive and more amenable one. Meanwhile, the above should serve as a cautionary tale that the canonical status of a phenomenon in psychological science and its widespread inclusion in handbooks of psychology should not be taken as a proxy for its empirical reliability and robustness. 


\section{ETHICAL APPROVAL}

All procedures performed were approved by the applicable ethics committees and in accordance with applicable guidelines and regulations.

\section{ACKNOWLEDGEMENTS}

The research reported here and the preparation of the current manuscript were supported by Research Grant G.0766.11N of the Fund for Scientific Research (FWO - Flanders) awarded to Tom Beckers, Rudi D'Hooge and Jan De Houwer, InterUniversity Attraction Pole grant P7/33 of the Belgian Science Policy Office awarded to Tom Beckers and Jan De Houwer, and KU Leuven Program Funding grant $\mathrm{PF} / 10 / 005$ awarded to Tom Beckers.

Part of the data, results and ideas contained in this paper have been reported at the First Joint Portuguese-Spanish Meeting on Comparative Psychology in Braga, Portugal, September 2014.

The authors thank Mark Haselgrove for his comments on earlier versions of the manuscript and Zsuzsanna Callaerts-Vegh, Dennis Garlick, Hannelore Goddeyn, Kenneth Leising and Jared Wang for their assistance in data collection. 


\section{REFERENCES}

Allen, M. T., Padilla, Y., Myers, C. E., \& Gluck, M. a. (2002). Selective hippocampal lesions disrupt a novel cue effect but fail to eliminate blocking in rabbit eyeblink conditioning. Cognitive, Affective \& Behavioral Neuroscience, 2, 318-28. Retrieved from http://www.ncbi.nlm.nih.gov/pubmed/12641176

Arcediano, F., Escobar, M., \& Matute, H. (2001). Reversal from blocking in humans as a result of posttraining extinction of the blocking stimulus. Animal Learning \& Behavior, 29, 354-366. doi:10.3758/BF03192901

Arcediano, F., Escobar, M., \& Miller, R. R. (2004). Is stimulus competition an acquisition deficit or a performance deficit? Psychonomic Bulletin \& Review, 11, 1105-1110. doi:10.3758/BF03196744

Bargh, J. a. (2006). What have we been priming all these years? On development, mechanisms, and ecology of nonconsious social behavior. European Journal of Social Psychology, 36, 147-168. doi:10.1002/ejsp.336.What

Bargh, J. A., Chen, M., \& Burrows, L. (1996). Automaticity of social behavior: Direct effects of trait construct and stereotype activation on action. Journal of Personality and Social Psychology, 71, 230-244. doi:10.1037/0022-3514.71.2.230

Beckers, T., Miller, R. R., De Houwer, J., \& Urushihara, K. (2006). Reasoning rats: forward blocking in Pavlovian animal conditioning is sensitive to constraints of causal inference. Journal of Experimental Psychology: General, 135, 92-102. doi:10.1037/0096-3445.135.1.92

Blaisdell, A. P., Gunther, L. M., \& Miller, R. R. (1999). Recovery from blocking achieved by extinguishing the blocking CS. Animal Learning \& Behavior, 27, 63-76.

Blaser, R. E., Couvillon, P. a, \& Bitterman, M. E. (2006). Blocking and pseudoblocking: new 
control experiments with honeybees. Quarterly Journal of Experimental Psychology (2006), 59, 6876. doi:10.1080/17470210500242938

Boddez, Y., Baeyens, F., Hermans, D., \& Beckers, T. (2011). The hide-and-seek of retrospective revaluation: recovery from blocking is context dependent in human causal learning. Journal of Experimental Psychology: Animal Behavior Processes, 37, 230-40. doi:10.1037/a0021460

Boddez, Y., De Houwer, J., \& Beckers T. (in press). The inferential reasoning theory of causal learning: Towards a multi-process propositional account. In M. Waldmann (Ed.), Oxford Handbook of Causal Reasoning. Oxford UK: Oxford University Press

Boddez, Y., Haesen, K., Baeyens, F., \& Beckers, T. (2014). Selectivity in associative learning : A cognitive stage framework for blocking and cue competition phenomena. Frontiers in Psychology, 5:1305. doi:10.3389/fpsyg.2014.01305

Bush, R. R., \& Mosteller, F. (1951). A mathematical model for simple learning. Psychological Review, 58, 313-323.

Colombo, M. (2014). Deep and beautiful. The reward prediction error hypothesis of dopamine. Studies in History and Philosophy of Science Part C: Studies in History and Philosophy of Biological and Biomedical Sciences, 45, 57-67. doi:10.1016/j.shpsc.2013.10.006

Corlett, P. R., Aitken, M. R. F., Dickinson, A., Shanks, D. R., Honey, G. D., Honey, R. a E., ... Fletcher, P. C. (2004). Prediction error during retrospective revaluation of causal associations in humans: fMRI evidence in favor of an associative model of learning. Neuron, $44,877-88$. doi:10.1016/j.neuron.2004.11.022

De Houwer, J. D. (2011). Why the Cognitive Approach in Psychology Would Profit From a Functional Approach and Vice Versa. Perspectives on Psychological Science, 6, 202-209. doi:10.1177/1745691611400238

De Houwer, J., Beckers, T., \& Glautier, S. (2002). Outcome and cue properties modulate 
blocking. The Quarterly Journal of Experimental Psychology, 55A, 965-985.

doi:10.1080/0272498014300057

Delamater, A., \& Lattal, K. M. (2014). The study of associative learning: Mapping from psychological to neural levels of analysis. Neurobiology of Learning and Memory, 108, 1-4. doi: 10.1016/j.nlm.2013.12.006.

den Ouden, H. E. M., Friston, K. J., Daw, N. D., Mclntosh, A. R., \& Stephan, K. E. (2009). A dual role for prediction error in associative learning. Cerebral Cortex, 19, 1175-85. doi:10.1093/cercor/bhn161

Dickinson, A., Shanks, D., \& Evenden, J. (1984). Judgement of act-outcome contingency: The role of selective attribution. The Quarterly Journal of Experimental Psychology Section A: Human Experimental Psychology, 36, 29-50. Retrieved from http://www.tandfonline.com/doi/abs/10.1080/14640748408401502

Dienes, Z. (2011). Bayesian Versus Orthodox Statistics: Which Side Are You On? Perspectives on Psychological Science, 6, 274-290. doi:10.1177/1745691611406920

Dijksterhuis, A., \& van Knippenberg, A. (1998). The relation between perception and behavior, or how to win a game of trivial pursuit. Journal of Personality and Social Psychology, 74, 865-877. doi:10.1037/0022-3514.74.4.865

Dopson, J. C., Pearce, J. M., \& Haselgrove, M. (2009). Failure of retrospective revaluation to influence blocking. Journal of Experimental Psychology: Animal Behavior Processes, 35, 473-484. doi:10.1037/a0014907

Doyen, S., Klein, O., Pichon, C.-L., \& Cleeremans, A. (2012). Behavioral Priming: It's All in the Mind, but Whose Mind? PLOS ONE, 7, e29081. doi:10.1371/journal.pone.0029081

Faul, F., Erdfelder, E., Lang, A.-G., \& Buchner, A. (2007). G*Power 3: A flexible statistical power analysis program for the social, behavioral, and biomedical sciences. Behavior Research 
Methods, 39, 175-191.

Feldman, J. M. (1975). Blocking as a function of added cue intensity. Animal Learning \& Behavior, 3, 98-102. doi:10.3758/BF03209108

Gallistel, C. R. (2009). The importance of proving the null. Psychological Review, 116, 43953. doi:10.1037/a0015251

Gomes, C. M., \& McCullough, M. E. (2015). The effects of implicit religious primes on dictator game allocations: A preregistered replication experiment. Journal of Experimental Psychology: General, 144, e94-e104. doi: 10.1037/xge0000027

Gray, T., \& Appignanesi, A. A. (1973). Compound Conditioning : Elimination of the Blocking Effect. Learning and Motivation, 4, 374-380.

Holland, P. C. (1988). Excitation and inhibition in unblocking. Journal of Experimental Psychology: Animal Behavior Processes, 14, 261-279. doi:10.1037/0097-7403.14.3.261

Holland, P. C. (1999). Overshadowing and Blocking as Acquisition Deficits : No Recovery After Extinction of Overshadowing or Blocking Cues. The Quarterly Journal of Experimental Psychology Section B, 52, 307-333.

Holland, P. C., \& Gallagher, M. (1993). Effects of Amygdala Central Nucleus Lesions on Blocking and Unblocking. Behavioral Neuroscience, 107, 235-245.

Janisiewicz, A. M., \& Baxter, M. G. (2003). Transfer effects and conditional learning in rats with selective lesions of medial septal/diagonal band cholinergic neurons. Behavioral Neuroscience, 117, 1342-52. doi:10.1037/0735-7044.117.6.1342

Jeffreys, H. (1961). The theory of probability. Oxford, UK: Oxford University Press.

Jennings, D., \& Kirkpatrick, K. (2006). Interval duration effects on blocking in appetitive conditioning. Behavioural Processes, 71, 318-329. doi:10.1016/j.beproc.2005.11.007 
Jones, D., \& Gonzalez-Lima, F. (2001). Mapping Pavlovian conditioning effects on the brain: blocking, contiguity, and excitatory effects. Journal of Neurophysiology, 86, 809-823.

Jones, P. M., \& Haselgrove, M. (2013). Blocking and associability change. Journal of Experimental Psychology: Animal Behavior Processes, 39, 249-58. doi:10.1037/a0032254

Kamin, L. J. (1969) Predictability, surprise, attention, and conditioning. In B. A. Cambell \& R. M. Church (Eds.), Punishment and aversive behavior. New York: Appleton-Century-Crofts.

LoLordo, V. M., Jacobs, W. J., \& Foree, D. D. (1982). Failure to block control by a relevant stimulus. Animal Learning \& Behavior, 10, 183-192. doi:10.3758/BF03212268

Love, J., Selker, R., Marsman, M., Jamil, T., Dropmann, D., Verhagen, A. J., Ly, A., Gronau, Q. F., Smira, M., Epskamp, S., Matzke, D., Wild, A., Knight, P., Rouder, J. N., Morey, R. D., \& Wagenmakers, E.-J. (2015). JASP (Version 0.7.1) [Computer software].

Ly, A., Verhagen, A. J., \& Wagenmakers, E.-J. (in press). Harold Jeffreys's default Bayes factor hypothesis tests: Explanation, extension, and application in psychology. Journal of Mathematical Psychology.

Mackintosh, N. J. (1971). An analysis of overshadowing and blocking. Quarterly Journal of Experimental Psychology, 23, 118-125. doi:10.1080/00335557143000121

Mackintosh, N. J. (1975). A theory of attention: Variations in the associability of stimuli with reinforcement. Psychological Review, 82, 276-298. doi:10.1037/h0076778

Mackintosh, N. J., Dickinson, A., \& Cotton, M. M. (1980). Surprise and blocking: Effects of the number of compound trials. Animal Learning \& Behavior, 8, 387-391. doi:10.3758/BF03199622

Merchant, H., \& Moore, J. (1973). Blocking of the rabbit's conditioned nictitating membrane response in Kamin's two-stage paradigm. Journal of Experimental Psychology, 101, 155-158. Retrieved from http://psycnet.apa.org/journals/xge/101/1/155/

Miller, R. R., \& Matzel, L. D. (1988). The comparator hypothesis: A response rule for the 
expression of associations. In G. H. Bower (Ed.), The psychology of learning and motivation (Vol. 22, pp. 51-92). San Diego, CA: Academic Press

Morey, R., D. (2015). Jasp and Bayes: A fresh way to do statistics [PowerPoint slides]. Retrieved from https://static.jasp-stats.org/presentations/August2015/RM/\#1

Morey, R. D., \& Rouder, J. N. (2015). BayesFactor: Computation of Bayes Factors for Common Designs. R package version 0.9.12-2. http://CRAN.R-project.org/package=BayesFactor

Parker, L. A. (1986). Drug-specific blocking of lithium-, amphetamine-, and apomorphineinduced conditioned flavor avoidance. Learning and Motivation, 17, 91-113. doi:10.1016/0023$9690(86) 90022-6$

Pavlov, I. P. (1927). Conditioned reflexes, an investigation of the physiological activity of the cerebral cortex. London: Oxford University Press.

Pearce, J. M.,\&Hall, G. (1980). A model for Pavlovian learning: Variation in the effectiveness of conditioned but not unconditioned stimuli. Psychological Review, 87, 532-552. doi:10.1037/0033$295 \times .87 .6 .532$

Pineño, O., Urushihara, K., \& Miller, R. R. (2005). Spontaneous recovery from forward and backward blocking. Journal of Experimental Psychology: Animal Behavior Processes, 31, 172-83. doi:10.1037/0097-7403.31.2.172

Prados, J., Alvarez, B., Acebes, F., Loy, I., Sansa, J., \& Moreno-Fernández, M. M. (2013). Blocking in rats, humans and snails using a within-subjects design. Behavioural Processes, 100, 2331. doi:10.1016/j.beproc.2013.07.014

R Core Team (2015). R: A language and environment for statistical computing. R Foundation for Statistical Computing, Vienna, Austria. URL https://www.R-project.org/.

Rescorla, R. A. (1999). Learning about qualitatively different outcomes during a blocking procedure. Animal Learning \& Behavior, 27, 140-151. doi:10.3758/BF03199671 
Rescorla, R. A. (2001). Are associative changes in acquisition and extinction negatively accelerated. Journal of Experimental Psychology: Animal Behavior Processes, 27, 307-315.

Rescorla, R. A., \& Wagner, A. R. (1972). A theory of Pavlovian conditioning: variations in the effectiveness of reinforcement and nonreinforcement. In Classical conditioning II: current research and theory (pp. 64-99).

Rodrigo, T., Chamizo, V. D., McLaren, I. P. L., \& Mackintosh, N. J. (1997). Blocking in the Spatial Domain. Journal of Experimental Psychology: Animal Behavior Processes, 23, 110-118.

Rouder, J. N., \& Morey, R. D. (2011). A Bayes factor meta-analysis of Bem's ESP claim. Psychonomic Bulletin \& Review, 18, 682-689. doi:10.3758/s13423-011-0088-7

Rouder, J. N., Speckman, P. L., Sun, D., Morey, R. D., \& Iverson, G. (2009). Bayesian t tests for accepting and rejecting the null hypothesis. Psychonomic Bulletin \& Review, 16, 225-237. doi:10.3758/PBR.16.2.225

Sahley, C., Rudy, J., \& Gelperin, A. (1981). An analysis of associative learning in a terrestrial mollusc. Journal of Comparative Physiology A, 144, 1-8. Retrieved from http://link.springer.com/article/10.1007/BF00612791

Schultz, W., \& Dickinson, A. (2000). Neuronal Coding of Prediction Errors. Annual Review of Neuroscience, $23,473-500$.

Shanks, D. R., Newell, B. R., Lee, E. H., Balakrishnan, D., Ekelund, L., Cenac, Z., ... Moore, C. (2013). Priming intelligent behavior: an elusive phenomenon. Plos One, 8, e56515-e56515. doi:10.1371/journal.pone.0056515

Sharriff, A.F., \& Norenzayan, A. (2015). A question of reliability or of boundary conditions? Comment on Gomes and McCullough (2015). Journal of Experimental Psychology: General, 144, e105-6. doi: 10.1037/xge0000111.

Smith, B., \& Cobey, S. (1994). The olfactory memory of the honeybee Apis mellifera. II. 
Blocking between odorants in binary mixtures. Journal of Experimental Biology, 195, 91-108.

Retrieved from http://jeb.biologists.org/content/195/1/91.short

Solomon, P. R. (1977). Role of the hippocampus in blocking and conditioned inhibition of the rabbit's nictitating membrane response. Journal of Comparative and Physiological Psychology, 91, 407-417. doi:10.1037/h0077330

Steinberg, E. E., Keiflin, R., Boivin, J. R., Witten, I. B., Deisseroth, K., \& Janak, P. H. (2013). A causal link between prediction errors, dopamine neurons and learning. Nature Neuroscience, 16, 966-73. doi:10.1038/nn.3413

Taylor, K. M., Joseph, V. T., Balsam, P. D., \& Bitterman, M. E. (2008). Target-absent controls in blocking experiments with rats. Learning \& Behavior, 36, 145-148. doi:10.3758/LB.36.2.145

Thalheimer, W., \& Cook, S. (2002). How to calculate effect sizes from published research articles: A simplified methodology. Retrieved February 14, 2016 from http://work-learning.com/effect_sizes.htm.

Tobler, P. N., O'doherty, J. P., Dolan, R. J., \& Schultz, W. (2006). Human neural learning depends on reward prediction errors in the blocking paradigm. Journal of Neurophysiology, 95, 30110. doi:10.1152/jn.00762.2005

van Overwalle, F., \& van Rooy, D. (2001). How One Cause Discounts or Augments Another: A Connectionist Account of Causal Competition. Personality and Social Psychology Bulletin, 27, 16131626. doi:10.1177/01461672012712005

Waelti, P., Dickinson, A., \& Schultz, W. (2001). Dopamine responses comply with basic assumptions of formal learning theory. Nature, 412, 43-48. doi:10.1038/35083500

Wagenmakers, E.-J. (2007). A practical solution to the pervasive problems of $p$ values. Psychonomic Bulletin \& Review, 14, 779-804. 
Wagenmakers, E.-J., Wetzels, R., Borsboom, D., \& van der Maas, H. L. J. (2011). Online Appendix for "Why Psychologists Must Change the Way They Analyze Their Data : The Case of Psi ": A Robustness Analysis. Journal of Personality and Social Psychology, 100, 426-432

Wagner, A. R. (1969). Stimulus validity and stimulus selection in associative learning. In N. J. Mackintosh \& W. K. Honig (Eds.), Fundamental issues in associative learning (pp. 90-122). Halifax, NS: Dalhousie University Press.

Wheeler, D. S., Beckers, T., \& Miller, R. R. (2008). The effect of subadditive pretraining on blocking: limits on generalization. Learning \& Behavior, 36, 341-51. doi:10.3758/LB.36.4.341

Williams, B. A. (1996). Evidence that blocking is due to associative deficit : Blocking history affects the degree of subsequent associative competition. Psychonomic Bulletin \& Review, 3, 71-74.

Willner, J. A. (1978). Blocking of a taste aversion by prior pairings of exteroceptive stimuli with illness. Learning and Motivation, 9, 125-140. doi:10.1016/0023-9690(78)90016-4 


\section{APPENDIX A}

Table A1

Comparison of experimental design and procedure employed in Series 1 to similar published studies

\begin{tabular}{|c|c|c|c|}
\hline & Experiments 1- 4 & $\begin{array}{l}\text { D. Jones \& Gonzalez- } \\
\text { Lima, } 2001\end{array}$ & $\begin{array}{l}\text { Mackintosh, Dickinson, } \\
\text { \& Cotton, } 1980\end{array}$ \\
\hline Animals & C57BL/6J mice & $\begin{array}{l}\text { Male Long-Evans black- } \\
\text { hooded rats }\end{array}$ & $\begin{array}{l}\text { Female hooded Lister } \\
\text { rats }\end{array}$ \\
\hline Control condition & B control & $\begin{array}{l}\text { Unpaired CS and US } \\
\text { presentations }\end{array}$ & B control \\
\hline $\mathrm{N}$ blocking & At least 10 & 6 & 12 \\
\hline $\mathrm{N}$ control & At least 10 & 7 & 12 \\
\hline Procedure & Aversive & Aversive & Aversive \\
\hline Dependent variable & SR of nose pokes & $\begin{array}{l}\text { SR of drinking behavior } \\
\text { and freezing }\end{array}$ & SR of licking response \\
\hline US & $\begin{array}{l}0.1-0.2 \mathrm{~mA} ; \\
\text { see Table B1 }\end{array}$ & $0.75-\mathrm{s}, 0.5-\mathrm{mA}$ & $0.5-\mathrm{s}, 0.75-\mathrm{mA}$ \\
\hline$A$ and $B$ & $\begin{array}{l}\text { Tones and lights; see } \\
\text { Table B1 }\end{array}$ & $\begin{array}{l}\text { A: two flashing white } \\
\text { lights } \\
\text { B: not used }\end{array}$ & $\begin{array}{l}\text { A : Overhead light; B: } \\
\text { Flashing light (not } \\
\text { counterbalanced) }\end{array}$ \\
\hline$x$ & $\begin{array}{l}\text { Tone or light; } \\
\text { see Table B1 }\end{array}$ & $\begin{array}{l}\text { Low-frequency FM } \\
\text { tone }\end{array}$ & $1800 \mathrm{~Hz}$ tone \\
\hline Duration CS & $10 \mathrm{~s}$ & $15 \mathrm{~s}$ & $60 \mathrm{~s}$ \\
\hline \# elemental pairings & $\begin{array}{l}\text { Between } 6 \text { and } 54 \text {; see } \\
\text { Table C1 }\end{array}$ & 16 & 4 \\
\hline \# compound pairings & Between 3 and 18; see & 12 & 2 \\
\hline
\end{tabular}


Table C1 
Table A2

Comparison of experimental design and procedure employed in Series 2 to similar published studies

\begin{tabular}{|c|c|c|c|}
\hline & Experiments 5-6 & Beckers et al., 2006 & $\begin{array}{l}\text { Wheeler, Beckers, \& } \\
\text { Miller, } 2008\end{array}$ \\
\hline Animals & $\begin{array}{l}\text { female Long-Evans } \\
\text { (Experiment 5) / } \\
\text { female Sprague- } \\
\text { Dawley (Experiment 6) }\end{array}$ & male Sprague-Dawley & male Sprague-Dawley \\
\hline Control condition & B control & B control & B control \\
\hline $\mathrm{N}$ blocking & 12 & 12 & 12 \\
\hline $\mathrm{N}$ control & 12 & 12 & 12 \\
\hline Procedure & Aversive & Aversive & Aversive \\
\hline Dependent variable & SR of lever pressing & SR of lever pressing & SR of lever pressing \\
\hline US & $0.5-\mathrm{s}, 0.5-\mathrm{mA}$ & $0.5-\mathrm{s}, 0.7-\mathrm{mA}$ & $0.5-\mathrm{s}, 0.7-\mathrm{mA}$ \\
\hline$A$ and $B$ & 300-Hz tone / clicker & $\begin{array}{l}300 \mathrm{~Hz} \text { tone / } 1900 \mathrm{~Hz} \\
\text { tone }\end{array}$ & $\begin{array}{l}\text { Low complex tone / } \\
1900 \mathrm{~Hz} \text { tone }\end{array}$ \\
\hline$x$ & White noise & Clicker & Clicker \\
\hline Duration CS & $30 \mathrm{~s}$ & $30 \mathrm{~s}$ & $30 \mathrm{~s}$ \\
\hline \# elemental pairings & 12 & 12 & 12 \\
\hline \# compound pairings & 4 & 4 & 4 \\
\hline \# test trials & 4 & 4 & 4 \\
\hline $\begin{array}{l}\text { Pretraining } \\
\text { procedure }\end{array}$ & $2 \mathrm{C}+/ \mathrm{D}+$ & $\begin{array}{l}C+/ D+/ E+o r \\
2 C+/ D E+\end{array}$ & $2 \mathrm{C}+/ \mathrm{D}+$ \\
\hline $\begin{array}{l}\text { \# pretraining } \\
\text { pairings }\end{array}$ & 12 & 12 & 12 \\
\hline
\end{tabular}


Table A3

Comparison of experimental design and procedure employed in Series 3 to similar published studies

\begin{tabular}{|c|c|c|}
\hline & Experiments 7-10 & Blaisdell et al., 1999 \\
\hline Animals & $\begin{array}{l}\text { Male (Experiments } 7 \& \\
\text { 8) and female } \\
\text { (Experiments } 9 \& 10 \text { ) } \\
\text { Sprague-Dawley rats }\end{array}$ & $\begin{array}{l}\text { Male and female } \\
\text { Sprague-Dawley rats }\end{array}$ \\
\hline Control condition & B control & B control \\
\hline $\mathrm{N}$ blocking & 4 & 6 \\
\hline $\mathrm{N}$ control & 4 & 6 \\
\hline Procedure & Aversive & Aversive \\
\hline Dependent variable & SR of lever pressing & $\begin{array}{l}\text { Mean times to lick for } \\
5 \text { cumulative seconds } \\
\text { in the presence of } X\end{array}$ \\
\hline US & $0.5-\mathrm{s}, 0.7-\mathrm{mA}$ & $0.5 \mathrm{~ms}, 1.0-\mathrm{mA}$ shock \\
\hline$A$ and $B$ & $\begin{array}{l}\text { 1000- } \mathrm{Hz} \text { tone / 3000- } \\
\mathrm{Hz} \text { tone }\end{array}$ & $\begin{array}{l}\text { complex tone ( } 3000 \\
\text { and } 3200 \mathrm{~Hz} \text { ) / white } \\
\text { noise }\end{array}$ \\
\hline$x$ & Clicker & Clicker \\
\hline Duration CS & $30 \mathrm{~s}$ & $10 \mathrm{~s}$ \\
\hline \# elemental pairings & 12 & 12 \\
\hline \# compound pairings & 4 & 4 \\
\hline \# test trials & 3 or 4 & $\begin{array}{l}\text { Presentation of } X \text { for a } \\
\text { maximum of } 15 \mathrm{~min}\end{array}$ \\
\hline
\end{tabular}

Note that the procedures from Beckers et al., 2006 and Wheeler et al., 2008, summarized in Table A2, are very similar as well. 
Table A4

Comparison of experimental design and procedure employed in Series 4 to similar published studies

\begin{tabular}{|c|c|c|c|}
\hline & Experiments $11-14$ & Holland, 1999, Exp. 6 & Taylor et al., 2008 \\
\hline Animals & $\begin{array}{l}\text { Female Sprague- } \\
\text { Dawley rats }\end{array}$ & $\begin{array}{l}\text { Female Sprague- } \\
\text { Dawley }\end{array}$ & male CRL:CD rats \\
\hline Control condition & B control & B control & B control \\
\hline $\mathrm{N}$ blocking & $\begin{array}{l}6 \text { (Experiments } 11 \& \\
12) / 12 \text { (Experiments } \\
13-14 \text { ) }\end{array}$ & 8 & 14 \\
\hline $\mathrm{N}$ control & $\begin{array}{l}6 \text { (Experiments } 11 \& \\
12 \text { ) / } 12 \text { (Experiments } \\
13-14 \text { ) }\end{array}$ & 8 & 14 \\
\hline Procedure & Appetitive & Appetitive & Appetitive \\
\hline Dependent variable & $\begin{array}{l}\text { Elevation of head } \\
\text { entries }\end{array}$ & Food cup behavior & $\begin{array}{l}\text { Number of head } \\
\text { entries }\end{array}$ \\
\hline US & Sucrose pellet & food pellet & 2 food pellets \\
\hline$A$ and $B$ & $\begin{array}{l}\text { Tone / clicker/ white } \\
\text { noise; see Table B1 }\end{array}$ & $\begin{array}{l}\text { A: noise; B: clicker; } \\
\text { not counterbalanced }\end{array}$ & $\begin{array}{l}\text { 1000-Hz tone / White } \\
\text { noise }\end{array}$ \\
\hline$x$ & $\begin{array}{l}\text { Tone / clicker/ white } \\
\text { noise; see Table B1 }\end{array}$ & Light & Bright light \\
\hline Duration CS & $10 \mathrm{~s}$ & $10 \mathrm{~s}$ & $12 \mathrm{~s}$ \\
\hline \# elemental pairings & $\begin{array}{l}\text { Between } 60 \text { and 100; } \\
\text { see Table B1 }\end{array}$ & 64 & 150 \\
\hline \# compound pairings & 20 & 32 & 50 \\
\hline \# test trials & 10 & 8 & 10 \\
\hline
\end{tabular}


Table A5

Comparison of experimental design and procedure employed in Series 5 to similar published studies

\begin{tabular}{|c|c|c|}
\hline & Experiment 15 & Taylor et al., 2008 \\
\hline Animals & male CRL:CD rats & male CRL:CD rats \\
\hline Control condition & B control & B control \\
\hline $\mathrm{N}$ blocking & 30 & 14 \\
\hline $\mathrm{N}$ control & 30 & 14 \\
\hline Procedure & Appetitive & Appetitive \\
\hline \multirow[t]{2}{*}{ Dependent variable } & Elevation of head & Number of head \\
\hline & entries & entries \\
\hline US & 2 food pellets & 2 food pellets \\
\hline \multirow[t]{2}{*}{$A$ and $B$} & 1000-Hz tone / White & 1000-Hz tone / White \\
\hline & noise & noise \\
\hline$x$ & Bright light & Bright light \\
\hline Duration CS & $12 \mathrm{~s}$ & $12 \mathrm{~s}$ \\
\hline \# elemental pairings & 150 & 150 \\
\hline \# compound pairings & 50 & 50 \\
\hline \# test trials & 10 & 10 \\
\hline
\end{tabular}




\section{APPENDIX B}

Table B1

Stimuli used in Experiments 1 to 15

Experiment

C/D

A/B

$\mathrm{X}$

$\mathrm{T}$

US

1

Flashing light / steady light Pulsing $3500-\mathrm{Hz}$

0.1-mA shock

tone

$1000 \mathrm{~Hz}$-tone / pulsing tone

Flashing light

0.1-mA shock

[1500 Hz and $2500 \mathrm{~Hz}$ ]

1000-Hz tone / pulsing tone

Flashing light

0.2-mA shock

[1500 Hz and $2500 \mathrm{~Hz}$ ]

4

Flashing light / steady light

Tone

0.2-mA shock

5-6

3000-Hz tone /

300-Hz tone / clicker

White noise

0.5-mA shock

flashing light

Clicker

0.7-mA shock

Pulsing $1000-\mathrm{Hz} /$ pulsing

Clicker

sucrose pellet

7000- $\mathrm{Hz}$ tone

13

$$
\text { Buzzer / flashing }
$$

Pulsing 1000-Hz / pulsing

Clicker

sucrose pellet

light 7000-Hz tone

14 Buzzer / flashing 1000-Hz tone / clicker

White noise $11000-\mathrm{Hz}$ sucrose pellet

light 


\section{APPENDIX C}

Table C1

Total number of trials in each phase

\begin{tabular}{|c|c|c|c|c|}
\hline Experiment & Habituation to & Pretraining & Phase 1: & Phase 2: \\
\hline & CS & & Elemental & Compound \\
\hline 1 & & & $6(2)$ & $3(1)$ \\
\hline 2 & & & $18\left(6^{a}\right)$ & $3(1)$ \\
\hline 3 & $3(1)^{b}$ & & $16(4)$ & $3(1)$ \\
\hline 4 & $3(1)^{c}$ & & $54(18)$ & $12(4)$ \\
\hline $5-6$ & & $12(4)^{d}$ & $12(3)$ & $4(1)$ \\
\hline $7-10$ & & & $12(3)$ & $4(1)$ \\
\hline 11 & & & $60(3)$ & $20(1)$ \\
\hline 12 & & & $80(4)$ & $20(1)$ \\
\hline 13 & & $105(5)^{d}$ & $80(4)$ & $20(1)$ \\
\hline 14 & & $252(12)^{d}$ & $100(5)$ & $20(1)$ \\
\hline 15 & & & $150(10)$ & 50 \\
\hline
\end{tabular}

Note. Number of days in each phase between brackets. ${ }^{\text {a }}$ Rats received two days of reshaping between the fifth and sixth day of elemental training; ${ }^{b}$ Habituation to $\mathrm{X} ;{ }^{\mathrm{c}}$ Habituation to $\mathrm{A}, \mathrm{B}$ and $\mathrm{X} ;{ }^{\mathrm{d}}$ Pretraining consisted out of $C+$ and $D+$ presentations with twice as many $C$ as $D$ trials. 
APPENDIX D

Table D1

Descriptives and results of one-tailed independent parametrical and Bayesian t-tests

conducted on test data (obtained with JASP 0.7.1, Love et al., 2015)

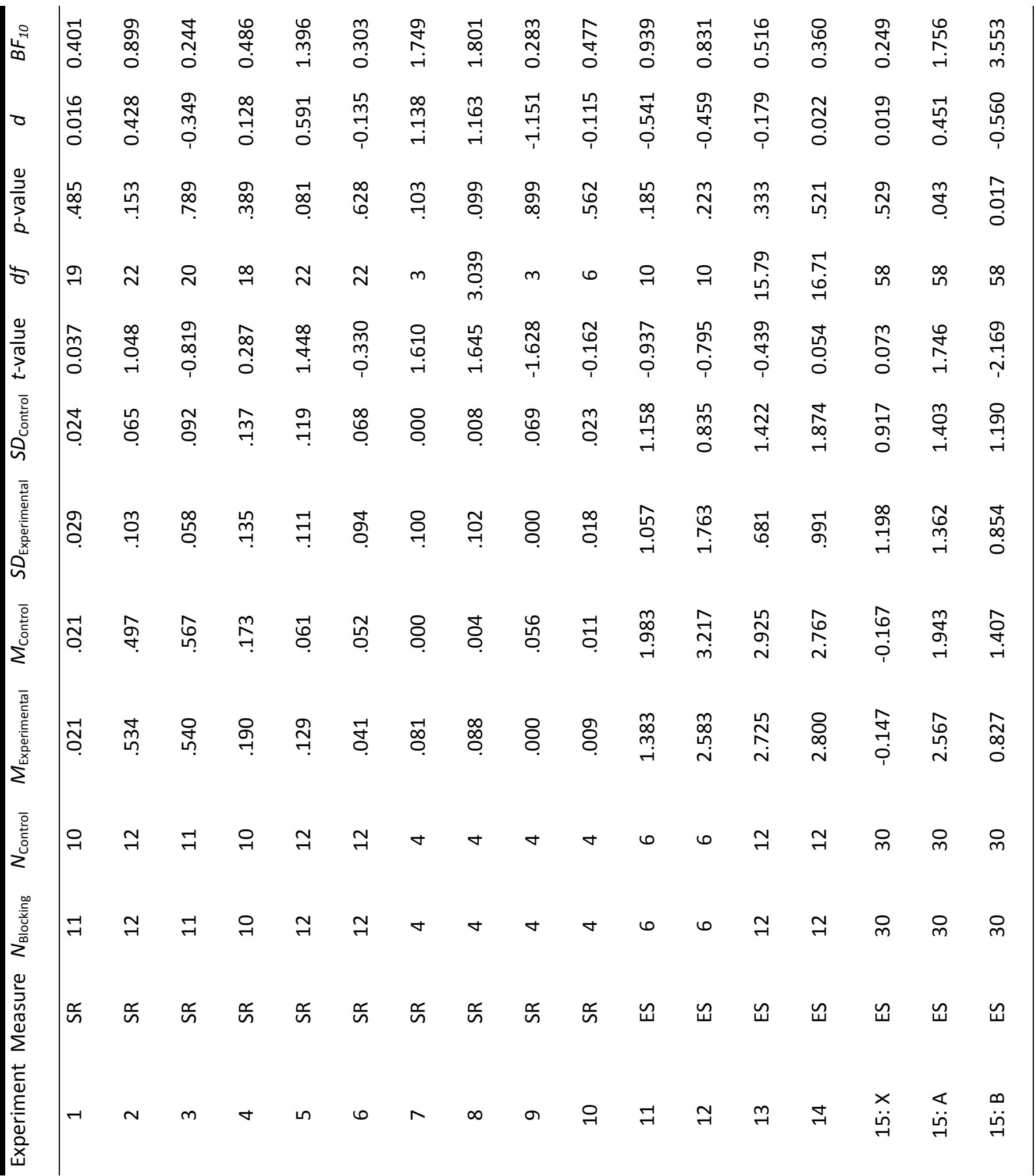


Note. SR: Suppression ratio; ES: Elevation score ; d : Cohen's d 
Table D2

Descriptives and results of two-tailed independent parametrical and Bayesian t-tests

conducted with JASP 0.7.1 (Love et al., 2015) on responding during first preCS interval at test

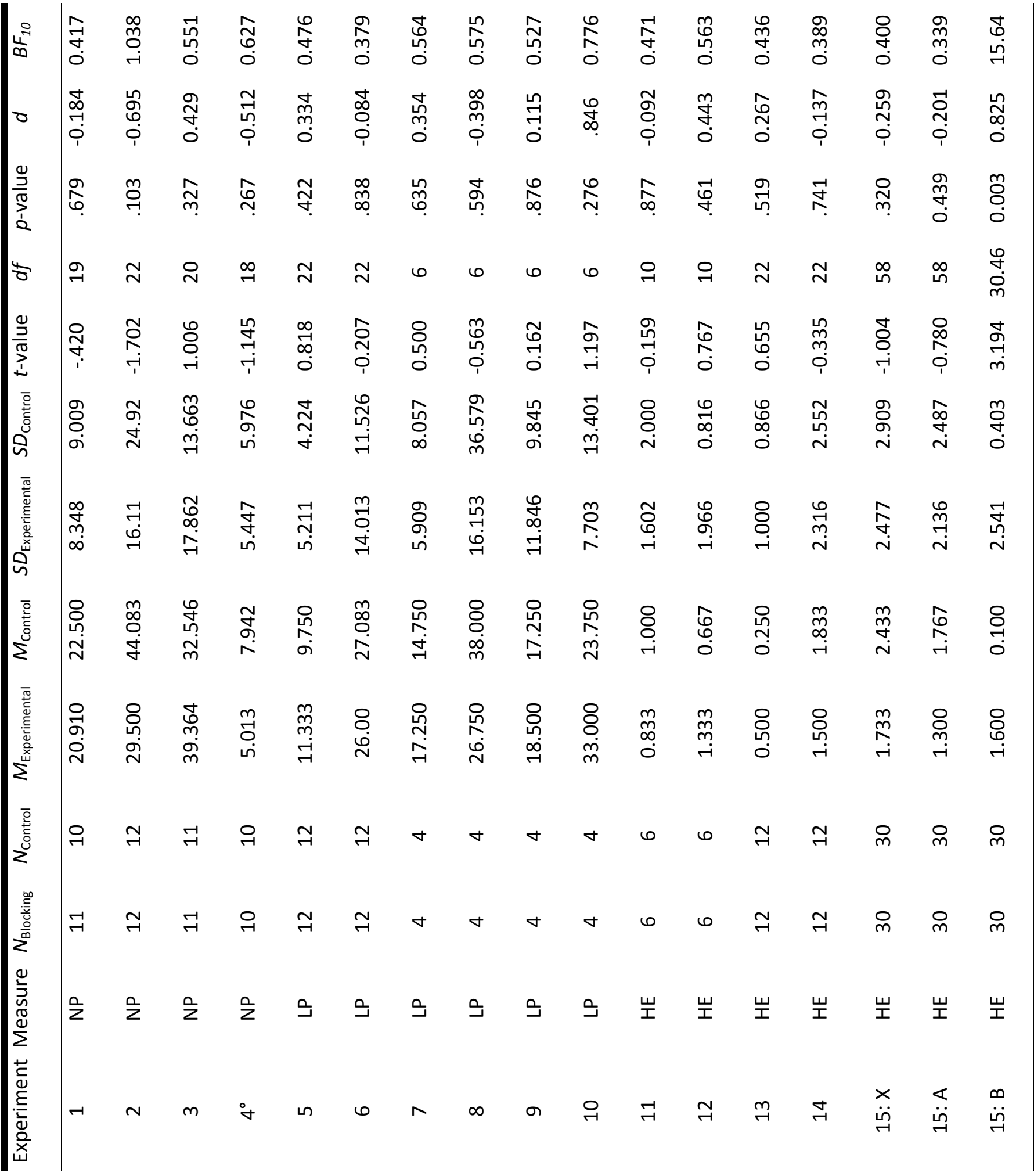


Note. NP: Nose pokes; LP: Lever presses; HE: Head entries; d: Cohen's d. ${ }^{\circ}$ For Exp. 4, the means and standard deviations are calculated over the test session because trial-level information was not available. 


\section{APPENDIX E}

The power analyses reported below are based on the effect sizes obtained in similar studies (see Appendix A). None of those studies reported the effect size based on the local error term. In case t- or F-values for the comparison between the relevant groups (blocking and control) using the local error term were reported, Cohen's $d$ was estimated using those reported values based on the formula of Thalheimer and Cook (2002). If $\mathrm{t}$ - or F-values for this comparison were not reported, estimations of the means and standard deviations from the reported figures were used to derive Cohen's d, again using the appropriate formula from Thalheimer and Cook (2002). For each series, an overall effect size, calculated as a weighted mean based on sample size, was then estimated. After calculating the overall effect size, power analyses were conducted with G*Power 3.1 (Faul, Erdfelder, Lang, \& Buchner, 2007).

\section{Series 1}

\section{Effect size}

D. Jones \& Gonzalez-Lima, 2001. Cohen's d = 1.83. Calculation of effect size was based on the F-value comparing freezing in the tone-blocked group with the tone-excitor group. Note that the effect size is possibly inflated due to use of an improper control group (unpaired control).

Mackintosh, Dickinson, \& Cotton, 1980. Insufficient data reported to calculate an effect size.

\section{Power analyses}

Experiment 1: $\beta=0.992$ (for one-tailed t-test and assuming $d=1.83$ )

Experiment 2: $\beta=0.996$ (for one-tailed t-test and assuming $d=1.83$ )

Experiment 3: $\beta=0.994$ (for one-tailed t-test and assuming $d=1.83$ )

Experiment 4: $\beta=0.989$ (for one-tailed t-test and assuming $d=1.83$ ) 


\section{Series 2}

Effect size

Beckers et al., 2006. Cohen's $d=1.81$ for irrelevant elemental pretraining and Cohen's $d=$ 2.13 for irrelevant compound pretraining (Note that those effect sizes differ slightly from the effect sizes reported by Beckers et al. (2006) because the reported effect sizes were based on the global error term).

Wheeler et al., 2008. Cohen's d = 3.23 effect size based on estimations of means and standard deviations of the irrelevant-control-no-shift group and irrelevant-blocking-no-shift group in the first block.

\section{Weighted effect size}

Cohen's $d_{\text {series } 2}=2.93$, effect size weighted based on sample size (see Table A2) for the three effect sizes reported above.

Power analysis

Experiment 5-6: $\beta>0.999$ (for one-tailed t-test and assuming $d=2.39$ ).

Series 3

Effect size

Blaisdell et al., 1999. Cohen's $d=1.79$, based on estimations of means and standard deviations for the two-phase blocking and control group.

Note that the procedures of Beckers et al., 2006 and Wheeler et al., 2008 were also very similar to the ones used in Series 3. Including the effect sizes of those studies in the power analysis would result in a higher power.

\section{Power analysis}

Experiment 7-10: $\beta=0.72$ (for one-tailed t-test and assuming $d=1.79$ ) 
Effect size

Holland, 1999 (Experiment 6). Cohen's $d=2.30$, based on estimations of means and standard deviations of the no-extinction blocking and no-extinction overshadowing group (= B control) and assuming that error bars represent standard error of the mean (in case error bars would represent standard deviations the effect size and thus the estimated power would be larger).

Taylor et al., 2008. Cohen's d =0.81, based on result of t-test for comparing blocking and control group.

Weighted effect size

Cohen's $d_{\text {series } 4}=1.35$, effect size weighted based on sample size (see Table A4) for the two effect sizes reported above.

Power analyses

Experiment 11-12: $\beta=0.70$ (for one-tailed t-test and assuming $d=1.35$ )

Experiment 13-14: $\beta=0.94$ (for one-tailed t-test and assuming $d=1.35$ )

Series 5

Effect size

Taylor et al., 2008. Cohen's $d=0.81$, based on result of t-test for comparing blocking and control group.

Power analysis

Experiment 15: $\beta=0.93$ (for one-tailed t-test and assuming $d=0.81$ ) 


\section{APPENDIX F}

Table F1

Descriptives and results of pairwise t-tests comparing conditioned responding to first and last presentation of $A$ or $B$ in elemental phase

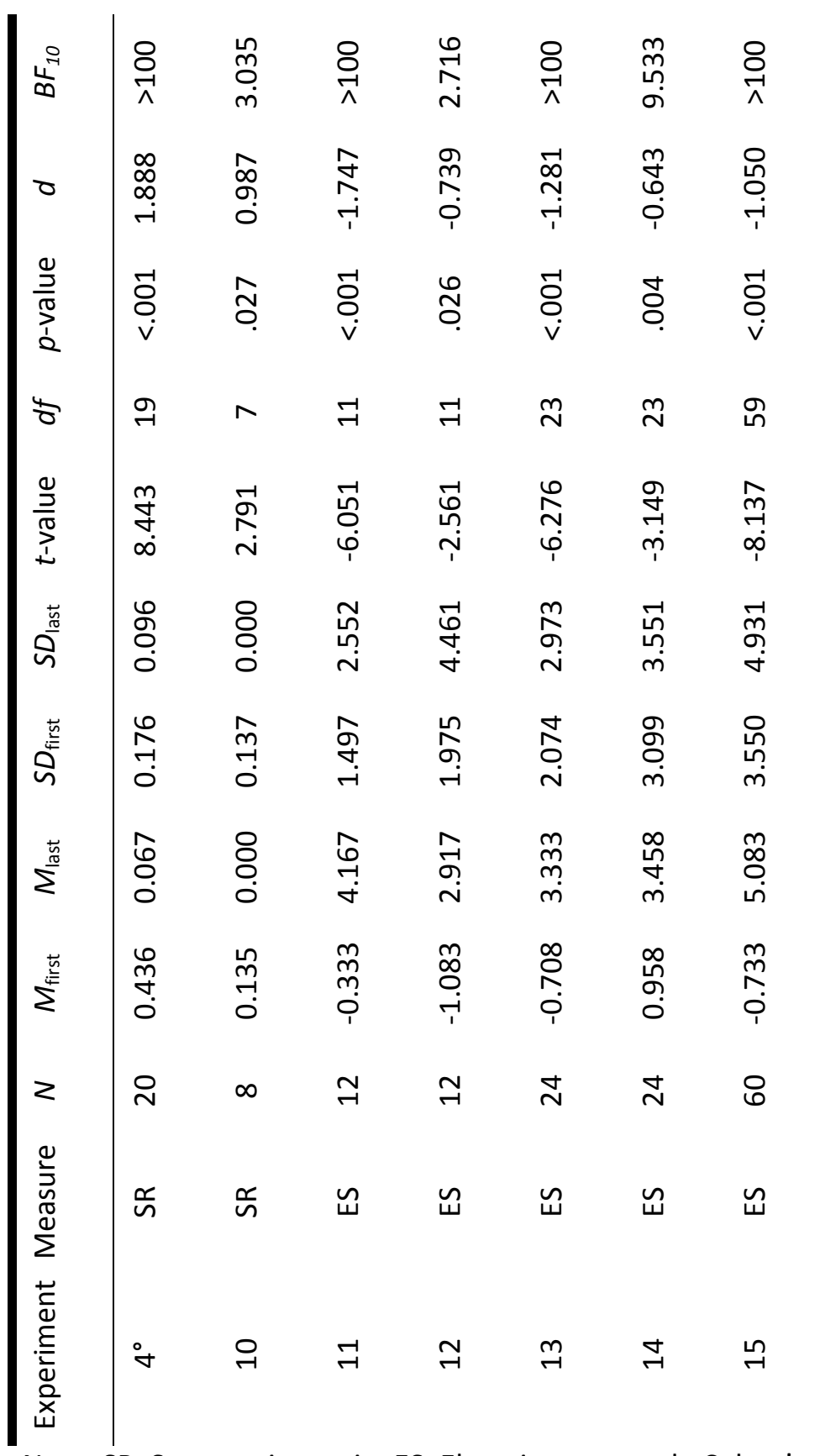

Note. SR: Suppression ratio; ES: Elevation score ; d : Cohen's d. ${ }^{\circ}$ For Exp. 4, the means and standard deviations are calculated over the entire first and last session because trial-level information was not available. 


\section{APPENDIX G}

Table G1

Results of Repeated Measures ANOVA with trial as within-subjects variable on last day of elemental training

\begin{tabular}{ccccccc}
\hline Experiment & Measure & $N$ & $F$-value & $d f$ & $p$-value & $\eta_{\text {partial }}{ }^{2}$ \\
\hline 10 & SR & 8 & 3.050 & 1,7 & 0.124 & 0.303 \\
11 & ES & 12 & 2.430 & 1,11 & .147 & 0.181 \\
12 & ES & 12 & .379 & 1,11 & .551 & 0.033 \\
13 & ES & 24 & 0.026 & 1,23 & .874 & 0.001 \\
14 & ES & 24 & 4.971 & 1,23 & .036 & 0.178 \\
15 & ES & 60 & 0.239 & 1,59 & .633 & 0.004
\end{tabular}

Note. This analysis was conducted using SPSS; it is not possible to conduct a Bayesian Repeated Measures

ANOVA with a within-subjects variable that consists out of more than three levels with JASP 0.7.1 (Love et al., 2015). 
Table G2

Descriptives and results of pairwise t-tests and Bayesian pairwise t-tests conducted with JASP 0.7.1 (Love et al., 2015) comparing conditioned responding to first and last presentation of $A$ or $B$ during the last elemental training session

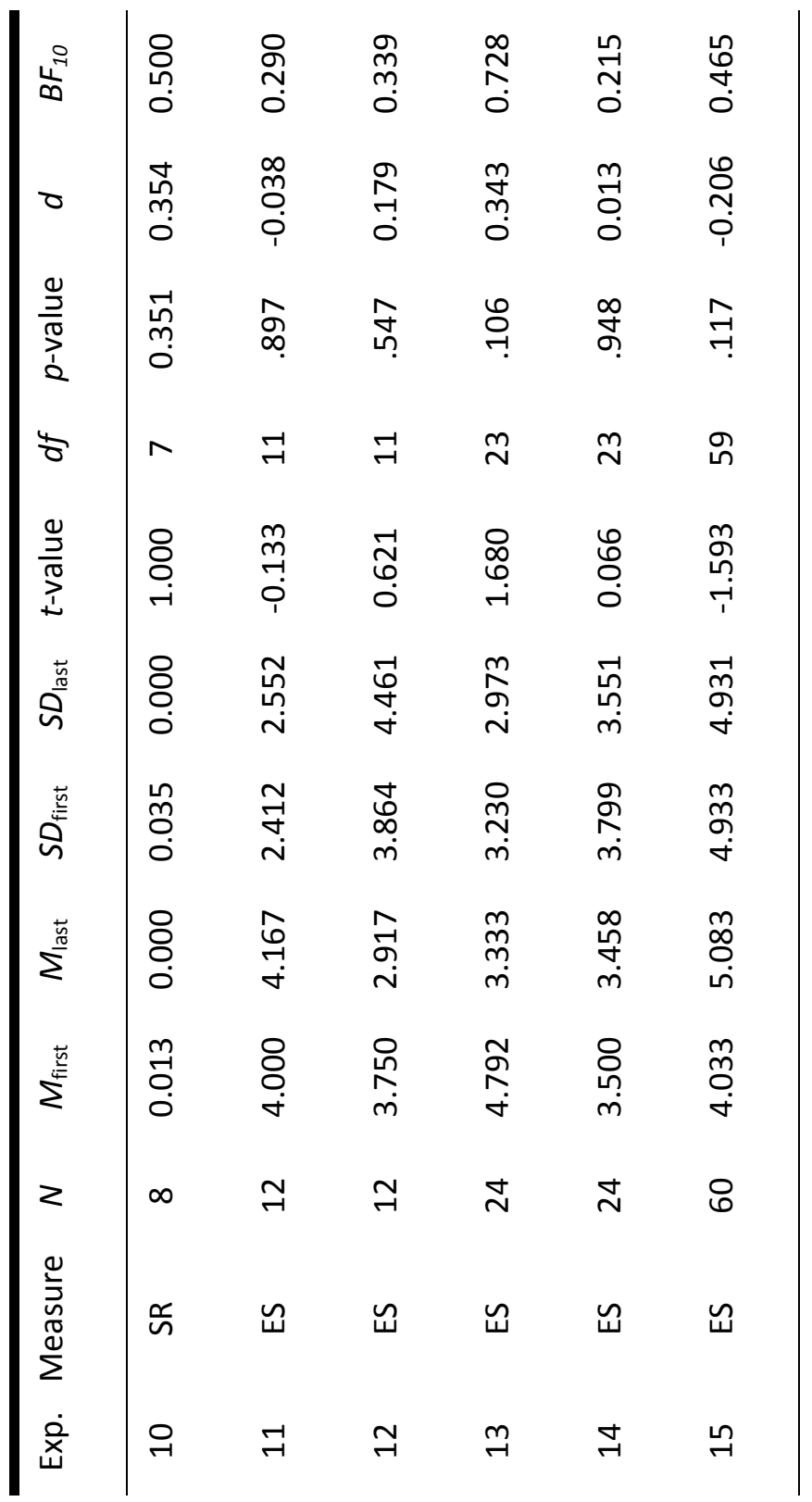

Note. SR: Suppression ratio; ES: Elevation score ; d : Cohen's d. 


\section{APPENDIX H}

Table $\mathrm{H} 1$

Descriptives and results of $t$-tests comparing conditioned responding to the first presentation of $A X$ in the compound phase between experimental and control groups

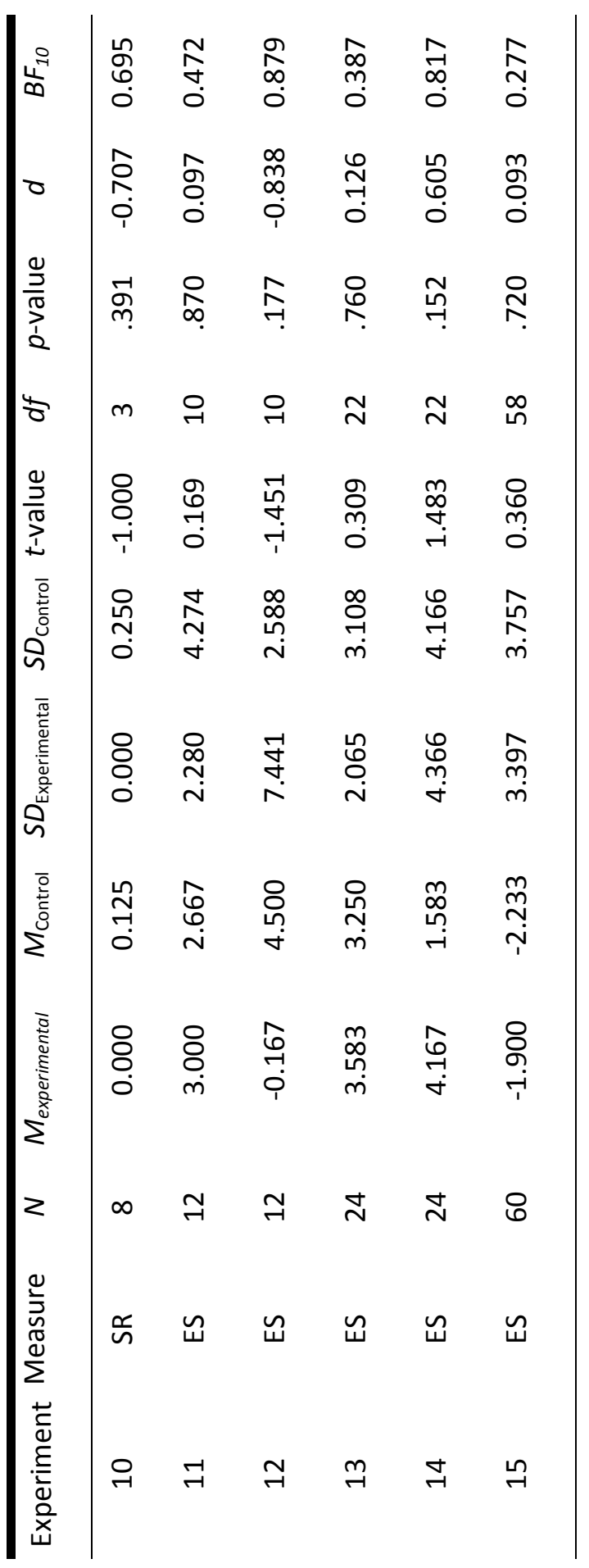

Note. SR: Suppression ratio; ES: Elevation score ; Cohen's d. 
APPENDIX I

Table I1

Descriptives and results of pairwise t-tests comparing conditioned responding to the last presentation of $A$ or $B$ in the elemental phase and the first presentation of $X$ at test

\begin{tabular}{|c|c|c|c|c|c|c|c|c|c|c|c|c|}
\hline$\frac{\text { î̀ }}{\infty}$ & & & $\begin{array}{l}\underset{+}{t} \\
\stackrel{0}{0}\end{array}$ & 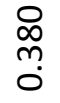 & 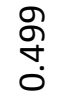 & 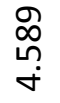 & 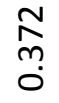 & $\begin{array}{l}\underset{\infty}{\infty} \\
0 \\
0\end{array}$ & 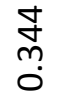 & $\underset{\substack{m \\
f \\
0}}{ }$ & $\begin{array}{l}\stackrel{8}{\circ} \\
\wedge\end{array}$ & $\underset{\wedge}{\stackrel{ }{1}}$ \\
\hline 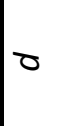 & \begin{tabular}{|l}
$\vec{\partial}$ \\
है \\
O \\
un
\end{tabular} & $\begin{array}{l}\vec{\partial} \\
\text { है } \\
\text { Ou }\end{array}$ & 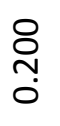 & $\begin{array}{l}\text { m } \\
\infty \\
0 \\
0\end{array}$ & $\begin{array}{l}\text { Nָ} \\
\text { } \\
\text { }\end{array}$ & $\begin{array}{l}\stackrel{P}{\text { }} \\
\stackrel{i}{i}\end{array}$ & \begin{tabular}{l}
$\stackrel{n}{N}$ \\
\multirow{1}{*}{}
\end{tabular} & $\begin{array}{l}\text { ホ } \\
\text { f } \\
\text { ì }\end{array}$ & $\begin{array}{l}\hat{\infty} \\
\stackrel{-1}{0} \\
0\end{array}$ & $\begin{array}{l}\stackrel{\varphi}{~} \\
\stackrel{m}{0} \\
\stackrel{0}{ }\end{array}$ & 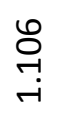 & $\begin{array}{l}\text { ֻூ } \\
\text { ọ }\end{array}$ \\
\hline$\frac{\frac{0}{2}}{\frac{1}{2}}$ & 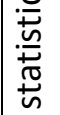 & 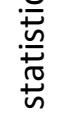 & \begin{tabular}{l}
\multirow{g}{*}{} \\
.
\end{tabular} & $\stackrel{\infty}{\infty}$ & $\stackrel{\infty}{\underset{\vartheta}{\sim}}$ & -े. & ฟิ & $\underset{\overbrace{}}{\stackrel{\overbrace{}}{-}}$ & $\stackrel{\overbrace n}{n}$ & શิ & $\begin{array}{l}-1 \\
8 \\
v\end{array}$ & $\overrightarrow{8}$ \\
\hline 4 & & & in & in & ம & in & 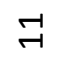 & 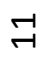 & $\exists$ & 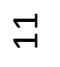 & શ & $\stackrel{\sim}{\sim}$ \\
\hline$\frac{\frac{\omega}{2}}{\frac{\pi}{2}}$ & & & $\begin{array}{l}\text { જ̆ } \\
\text { ণे }\end{array}$ & ণָ & $\begin{array}{l}n \\
0 \\
0 \\
0 \\
1\end{array}$ & $\begin{array}{l}\text { ñ } \\
\text { ஸे } \\
\text { r }\end{array}$ & $\begin{array}{l}0 \\
\stackrel{\infty}{0} \\
0 \\
1\end{array}$ & 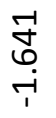 & 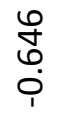 & $\begin{array}{l}\mathscr{~} \\
\text { ○े } \\
\stackrel{-}{-}\end{array}$ & $\begin{array}{l}8 \\
\varnothing \\
\emptyset\end{array}$ & 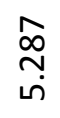 \\
\hline $0^{x}$ & O্் & ০ִ & $\begin{array}{l}\stackrel{\nabla}{\infty} \\
\infty \\
\dot{m}\end{array}$ & $\begin{array}{l}\stackrel{n}{\rightarrow} \\
\stackrel{-}{n}\end{array}$ & $\underset{m}{\stackrel{d}{N}}$ & $\begin{array}{l}\text { ถి } \\
\text { }\end{array}$ & $\underset{\underset{N}{N}}{\stackrel{\Omega}{N}}$ & $\begin{array}{l}\infty \\
\stackrel{\infty}{\circ} \\
\end{array}$ & $\begin{array}{l}\stackrel{\infty}{\infty} \\
\underset{m}{m}\end{array}$ & $\begin{array}{l}\hat{m} \\
\text { m} \\
m\end{array}$ & $\begin{array}{l}\stackrel{\sim}{+} \\
\stackrel{\infty}{N}\end{array}$ & $\underset{m}{\stackrel{+}{m}}$ \\
\hline $0^{4}$ & ৪্ & 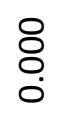 & $\begin{array}{l}\stackrel{\infty}{\infty} \\
\stackrel{-1}{m}\end{array}$ & 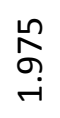 & 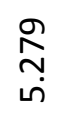 & $\begin{array}{l}\hat{m} \\
\text { m } \\
m\end{array}$ & $\begin{array}{l}\stackrel{n}{\hat{n}} \\
\tilde{n} \\
m\end{array}$ & 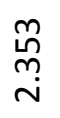 & $\begin{array}{l}\frac{0}{6} \\
\dot{n}\end{array}$ & $\begin{array}{l}\stackrel{n}{\stackrel{n}{-1}} \\
\stackrel{m}{m}\end{array}$ & $\begin{array}{l}\infty \\
\stackrel{\infty}{\infty} \\
\text { ம் }\end{array}$ & $\begin{array}{l}\stackrel{\infty}{\infty} \\
\stackrel{m}{m}\end{array}$ \\
\hline$\Sigma^{x}$ & $\begin{array}{l}8 \\
\circ \\
0\end{array}$ & $\begin{array}{l}8 \\
\text { ¿̊ } \\
0\end{array}$ & $\begin{array}{l}8 \\
\text { ำ } \\
\text { ஸ̣ }\end{array}$ & $\begin{array}{l}\hat{\sigma} \\
\stackrel{+}{\sigma}\end{array}$ & $\begin{array}{l}\hat{\theta} \\
\dot{\omega}\end{array}$ & $\begin{array}{l}8 \\
\text { ஸ̊ } \\
\text { ம் }\end{array}$ & $\begin{array}{l}\hat{\theta} \\
\dot{\sigma}\end{array}$ & $\begin{array}{l}m \\
\infty \\
0 \\
\text { م }\end{array}$ & $\begin{array}{l}\stackrel{f}{f} \\
\dot{m}\end{array}$ & $\begin{array}{l}\underset{f}{+} \\
\dot{m}\end{array}$ & $\begin{array}{l}\underset{m}{m} \\
\text { mo } \\
\stackrel{1}{1}\end{array}$ & $\begin{array}{l}8 \\
\stackrel{0}{0} \\
0\end{array}$ \\
\hline$\Sigma^{\alpha}$ & ৪ & $\begin{array}{l}8 \\
8 \\
0\end{array}$ & $\begin{array}{l}\underset{\infty}{\infty} \\
\stackrel{m}{m}\end{array}$ & $\begin{array}{l}\stackrel{8}{\circ} \\
\text { ํㅜ }\end{array}$ & $\stackrel{m}{m}$ & $\begin{array}{l}\text { 운 } \\
\text { ㅅ }\end{array}$ & $\begin{array}{l}m \\
\infty \\
\infty \\
m \\
m\end{array}$ & $\begin{array}{l}m \\
\infty \\
0 \\
\dot{m}\end{array}$ & 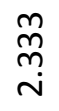 & $\begin{array}{l}\stackrel{m}{\infty} \\
\stackrel{\infty}{\sim} \\
\dot{\sim}\end{array}$ & $\begin{array}{l}\hat{Q} \\
\infty \\
\text { ம் }\end{array}$ & 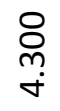 \\
\hline$z$ & $\nabla$ & $\sigma$ & 6 & 6 & 6 & 6 & $\approx$ & テ & $\underset{7}{ }$ & 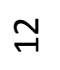 & ஜ & 이 \\
\hline $\begin{array}{l}\overline{3} \\
\bar{u} \\
0\end{array}$ & $\stackrel{r}{\sim}$ & $\stackrel{r}{n}$ & $\stackrel{\mathscr{c}}{\mathfrak{n}}$ & 出 & $\widetilde{w}$ & $\widetilde{山}$ & $\tilde{w}$ & 出 & 出 & $\breve{w}$ & 出 & $\widetilde{w}$ \\
\hline $\begin{array}{l}\text { 음 } \\
\text { 눈 }\end{array}$ & 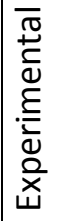 & $\begin{array}{l}\overline{0} \\
\text { 온 } \\
\text { Oे }\end{array}$ & 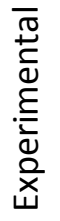 & $\begin{array}{l}\overline{0} \\
\frac{0}{2} \\
\overline{0}\end{array}$ & 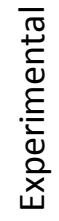 & $\begin{array}{l}\overline{0} \\
\underline{0} \\
\overline{0} \\
0\end{array}$ & 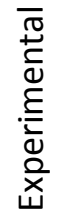 & 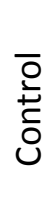 & 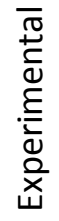 & 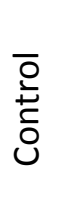 & 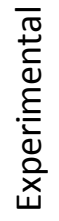 & 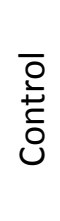 \\
\hline
\end{tabular}




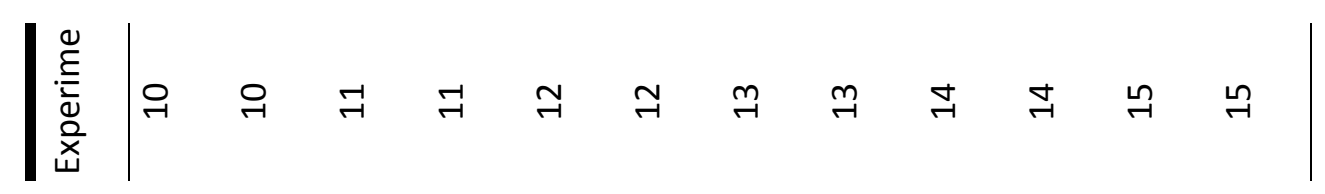

Note. SR: Suppression ratio; ES: Elevation score. 


\section{APPENDIX J}

Table J1

Overview of the additional blocking conditions (experimental versus control groups)

included in the extended Bayesian meta-analysis along with the experiments reported here. Means and standard deviations were estimated based on the reported figures.

\begin{tabular}{|c|c|c|c|c|c|c|}
\hline Experimental condition & $M_{\text {experimental }}$ & $M_{\text {control }}$ & $S D_{\text {experimental }}$ & $S D_{\text {control }}$ & $N_{\text {total }}^{1}$ & $t$-value \\
\hline $\begin{array}{l}\text { Beckers et al., 2006, Experiment 1, } \\
\text { Irrelevant element condition }\end{array}$ & 0.200 & 0.056 & 0.083 & 0.083 & 24 & 4.243 \\
\hline $\begin{array}{l}\text { Beckers et al., 2006, Experiment 1, } \\
\text { Irrelevant compound condition }\end{array}$ & 0.269 & 0.036 & 0.156 & 0.042 & 24 & 5.003 \\
\hline $\begin{array}{l}\text { Beckers et al., 2006, Experiment 2, } \\
\text { Additive condition }\end{array}$ & 0.139 & 0.040 & 0.156 & 0.048 & 24 & 2.101 \\
\hline $\begin{array}{l}\text { Beckers et al., 2006, Experiment 2, } \\
\text { Irrelevant element condition }\end{array}$ & 0.100 & 0.089 & 0.118 & 0.100 & 24 & 0.246 \\
\hline $\begin{array}{l}\text { Beckers et al., 2006, Experiment 2, } \\
\text { Irrelevant compound condition }\end{array}$ & 0.160 & 0.049 & 0.139 & 0.111 & 24 & 2.167 \\
\hline $\begin{array}{l}\text { Beckers et al., 2006, Experiment } 3 \text {, } \\
\text { Submaximal high condition }\end{array}$ & 0.145 & 0.035 & 0.097 & 0.038 & 24 & 3.657 \\
\hline $\begin{array}{l}\text { Beckers et al., 2006, Experiment } 3 \text {, } \\
\text { Submaximal low condition }\end{array}$ & 0.202 & 0.091 & 0.111 & 0.104 & 24 & 2.531 \\
\hline $\begin{array}{l}\text { Wheeler et al., 2008, Experiment 1, } \\
\text { Irrelevant no shift condition }{ }^{2}\end{array}$ & 0.451 & 0.100 & 0.135 & 0.087 & 24 & 7.577 \\
\hline $\begin{array}{l}\text { Wheeler et al., 2008, Experiment 1, } \\
\text { Subadditive shift condition }{ }^{2}\end{array}$ & 0.259 & 0.050 & 0.156 & 0.083 & 24 & 4.098 \\
\hline Wheeler et al., 2008, Exp. 2eriment & 0.163 & 0.033 & 0.135 & 0.052 & 24 & 3.111 \\
\hline
\end{tabular}


Long condition ${ }^{2}$

$\begin{array}{lllllll}\text { Wheeler et al., 2008, Experiment 3, } & 0.239 & 0.042 & 0.142 & 0.073 & 24 & 4.277\end{array}$

Difference condition ${ }^{2}$

Note. ${ }^{1 .}$ For all conditions the number of animals in the experimental and control group was equal. ${ }^{2 .}$ Data for the first two presentations of $X$ at test. 
